\title{
A three-dimensional approach to the Extended Limit Analysis of Reinforced Masonry
}

\section{Journal Article}

Author(s):

López López, David; Roca, Pere; Liew, Andrew; Méndez Echenagucia, Tomás; Van Mele, Tom; Block, Philippe

Publication date:

2022-01

Permanent link:

https://doi.org/10.3929/ethz-b-000523919

Rights / license:

Creative Commons Attribution-NonCommercial-NoDerivatives 4.0 International

Originally published in:

Structures 35, https://doi.org/10.1016/j.istruc.2021.06.013 


\title{
A three-dimensional approach to the Extended Limit Analysis of Reinforced Masonry
}

\author{
David López López $^{\text {a,*, Pere Roca }}{ }^{\text {a }}$, Andrew Liew ${ }^{\mathrm{b}}$, Tomás Méndez Echenagucia ${ }^{\mathrm{c}}$, \\ Tom Van Mele ${ }^{\mathrm{d}}$, Philippe Block ${ }^{\mathrm{d}}$
}

${ }^{a}$ Universitat Politècnica de Catalunya, Department of Civil and Environmental Engineering, Spain

${ }^{\mathrm{b}}$ The University of Sheffield, Department of Civil and Structural Engineering, United Kingdom

${ }^{\mathrm{c}}$ University of Washington, Department of Architecture, College of Built Environments, United States

${ }^{\mathrm{d}}$ ETH Zurich, Institute of Technology in Architecture, Block Research Group, Switzerland

\section{A R T I C L E I N F O}

\section{Keywords:}

Tile vault

Masonry

Reinforced brick

Formwork

Concrete shells

Limit analysis

Thrust Network Analysis

Extended Limit Analysis of Reinforced Masonry

\begin{abstract}
A B S T R A C T
The Extended Limit Analysis of Reinforced Masonry (ELARM) is a simple and user-friendly method for the design and structural analysis of singly-curved, reinforced tile vaults [1]. It is based on limit analysis but takes into account the reinforcement's contribution to the composite cross-section's bending capacity.

A three-dimensional approach to ELARM is presented in this paper. The theoretical framework to understand the implications and limitations of extending ELARM to fully 3D structures is described, together with the strategies to carry out the leap from $2 \mathrm{D}$ to $3 \mathrm{D}$. This extension is a lower-bound approach for the design of reinforced masonry, reinforced concrete and concrete-masonry composite shells and the assessment of their strength and stability against external loading.

The new, extended method is implemented computationally to speed up the iterative processes, provide quick structural feedback, offer immediate results and allow for user-interactive form-finding and optimisation procedures. Different applications of the developed tool are described through the presentation of examples, including reinforcement optimisation, a form-finding process and a case with a shape beyond funicular geometry.
\end{abstract}

\section{Introduction}

The Extended Limit Analysis of Reinforced Masonry, ELARM, was presented in López López et al. (2019) [1] as a 2D method for the design and structural analysis of composite structures consisting of tile vaults as integrated formwork for reinforced concrete.

Tile vaults (also known as Catalan, thin-tile or Guastavino vaults) are traditional unreinforced masonry structures made of tiles (thin bricks) and binder. Thanks to the lightness of the bricks and the use of fastsetting binders, they can be built "in space", without formwork, which makes them inherently economic [2]. The tile vault's versatility, economy, sustainability, efficiency and expressiveness have drawn the attention of current architects, designers and engineers, who have recovered this ancient technique in a series of recent projects that, thanks to the new available computational tools, highlight the capability of tile vaults to shape appealing, complex, free-form, masonry structures [3 $\left.4 \begin{array}{lllll} & 5 & 6 & 7 & 8\end{array}\right]$.

Tile vaults can be used as stay-in-place formwork for reinforced concrete to build inexpensive and expressive concrete shells [9 1]. The costs and waste are significantly reduced due to the possibility to eliminate the need of traditional formwork, while the tile vault provides a unique finish at the intrados. The reinforcement is placed and the concrete is poured on the masonry vault, creating a composite system (Fig. 1), capable of resisting tensile stresses and bending moments and thus allowing structures beyond the masonry's compression-only restriction.

This paper presents a lower-bound method for the design and analysis in 3D of composite shells built using tile vaults as integrated formwork for reinforced concrete. It is also applicable to shells of other kinds of reinforced masonry, reinforced concrete or the combination of them. This research follows up López López et al. (2019) [1], where the mentioned construction technique and the design and structural analysis method for two-dimensional structures was presented together with experimental research on material samples and barrel vaults. ELARM uses traditional 2D limit analysis [10] on a vault whose thickness had been virtually increased accounting for the tensile and bending capacity

\footnotetext{
* Corresponding author.

E-mail address: david.lopez.lopez@upc.edu (D. López López).
} 

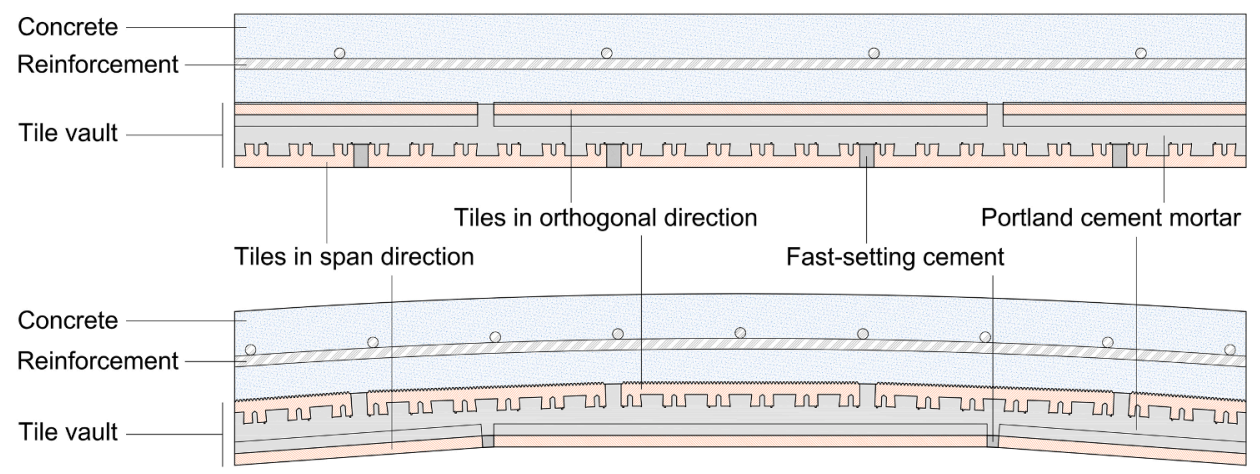

Fig. 1. Typical transversal and longitudinal cross sections of the composite system. Featuring a two-layered tile vault and reinforced concrete [1].

provided by the reinforcement and considering also a limited compressive strength of both masonry and concrete.

A description of the research's background is made in Section 2, followed by the presentation of ELARM's extension to fully 3D structures in Section 3. The method's computational implementation is presented in Section 4. The last section before the conclusions is Section 5, which presents examples of different applications of the method.

\section{Background}

The design and structural analysis method for singly-curved, reinforced, masonry vaults described in López López et al. (2019) [1] is based on traditional limit analysis and plastic theorems -safe and uniqueness theorems- [10], but takes into account the limited compressive strength of the materials and the tensile and bending capacity of the reinforcement. The method analyses the cross sections along the vault's span to obtain their ultimate positive and negative bending moments, with which maximum eccentricities for a given axial load can be determined [11 1 ]. The eccentricities related to the positive and negative bending moments define, respectively, the new upper and lower fictitious boundaries of the vault with which the limit analysis is graphically performed. The axial load (and thus the fictitious boundaries as well) varies along the vault's span depending on the self-weight and the external loads and is obtained by analytically determining a thrust line.

Limit analysis was also proposed as a method for the analysis of reinforced masonry by Lourenço et al. [12] and Roca et al. [11], and unreinforced masonry including tensile capacity by Ramaglia et al. [13] and Fabbrocino et al. [14]. The experimentally-verified algorithm in ELARM [1] is an extension of the one in Roca et al. [11], including important differences and improvements such as: 1) the incorporation of different materials in the structural sections and the associated crosssection equilibrium implementations and design code checks, 2) the consideration of different failure modes and its adaptation to the presented specific composite structural typology, and 3) a robust and interactive computational implementation that provides a powerful design and analysis tool, exemplified with many practical design examples. More recently, research by Zampieri et al. [15 16] described the use of limit analysis to assess masonry arch bridges strengthened with fibre reinforced cementitious matrices or steel fibre reinforced mortars.

In all the mentioned cases, the presented analysis methods are twodimensional, aimed at the assessment of arched or singly-curved structures. However, the approach described in this paper is a further extension of ELARM to design and assess fully-3D structures.

The leap from 2D to 3D equilibrium analysis is not straightforward or direct. It has been only in the last decade that significant advances with practical and useful results have been made. Thrust Network Analysis (TNA) [17 18] was the beginning of a series of advances in the field by Prof. Dr. Philippe Block and the Block Research Group (BRG, ETH Zurich), such as the use of constraint-based and parametric software to provide continuous, bi-directional control over both spatial and structural characteristics [19], a computational framework based on TNA and a user-friendly software implementation [20] and optimization algorithms for the 3D equilibrium analysis of unreinforced masonry vaults [21]. Contributions to the field have been also made by, among others, Fraternali (2010), presenting a constrained thrust network approach for the prediction of the thrust surface and the crack pattern of vaulted masonry structures [22], Vouga et al. (2012), introducing new methods of discrete differential geometry to build on relations between statics and geometry [23], and De Goes et al. (2013), whose work on simplicial

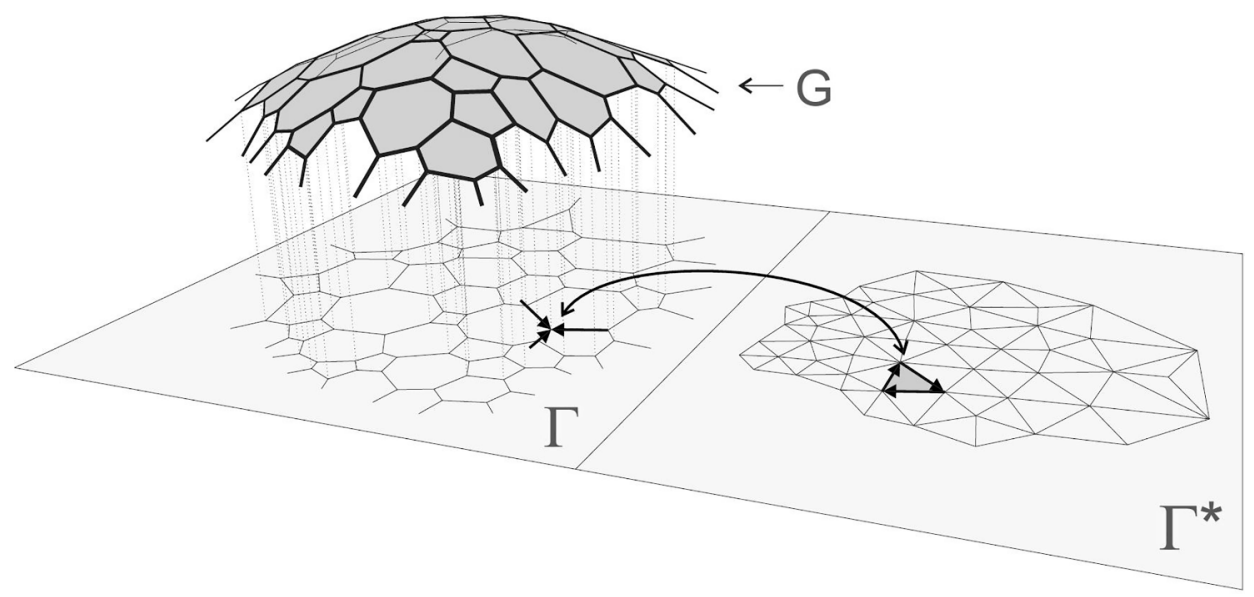

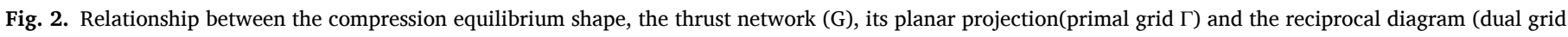
$\left.\Gamma^{*}\right)\left[\begin{array}{ll}17 & 18\end{array}\right]$. 


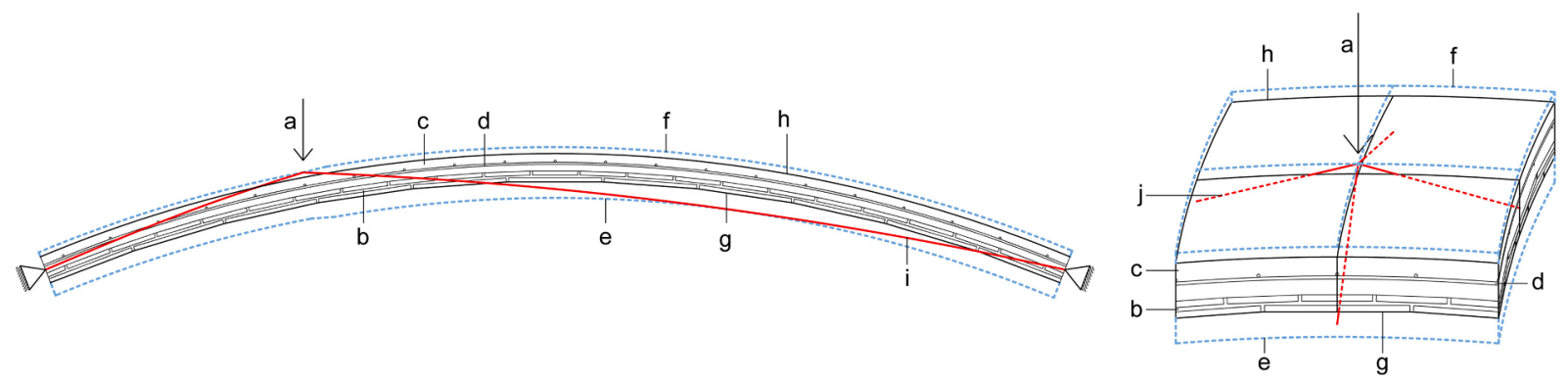

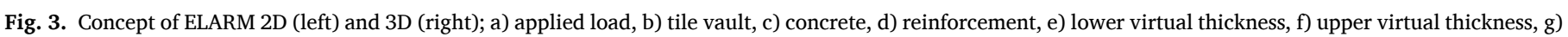
real lower thickness, h) real upper thickness, i) thrust line, and j) thrust network.

masonry provides a discrete theory of equilibrium for self-supporting, compression-only structures [24].

TNA provides a graphical and intuitive method for the design and equilibrium assessment of compression-only shell structures under gravitational and/or vertical loads [17]. As traditional limit analysis is the base for ELARM in 2D [1], TNA is the base for the extension in 3D.

\subsection{Thrust network}

The thrust network is the three-dimensional extension of the thrust line, i.e., a spatial representation of compressive force resultants in equilibrium with the applied loads. It is represented by edges and vertices. The edges are the linear elements connecting the vertices of the network. It is obtained using Thrust Network Analysis (TNA). TNA uses projective geometry, duality theory and linear optimisation to provide intuitive results and offers a clear graphical representation of forces in the system through reciprocal force diagrams to visualize the proportional relationship of the horizontal forces in the network [17 18].

The thrust network needs as input a primal grid or form diagram, which is the vertical projection in the horizontal plane of the funicular equilibrium solution, i.e., a pattern to define the network topology (Fig. 2, Г). From this pattern, whose branches represent possible load paths throughout the structure, the horizontal equilibrium is computed, resulting in a force diagram (Fig. $2, \Gamma^{*}$ ) that the user can manipulate to obtain different force distributions (and thus different final thrust networks at the end of the process (Fig. 2, G)). The dual grid $\Gamma^{*}$ is produced from the primal grid $\Gamma$ by solving two consecutive linear optimisation problems, described in Block (2009) [17], according to Maxwell's definition of reciprocal figures [25]: corresponding branches stay parallel and the equilibrium of a node in one grid is guaranteed by a closed polygon in the other and vice versa (Fig. 2) [18].

The vertical equilibrium is analysed afterwards using a one-step linear optimization, as described in Block (2009) [17], considering the geometry of both primal $(\Gamma)$ and dual $\left(\Gamma^{*}\right)$ grids, the weights applied at the nodes and the boundary conditions. The result is a thrust network in equilibrium, from which internal forces, $f$, can be extracted.

The definition of the specific primal grid determines the outcome of any application of TNA, as thoroughly described, among others, in Block and Ochsendorf (2007) [18] and Block (2009) [17].

\subsection{Safe or lower bound theorem}

Heyman's plastic theorems applied to limit analysis in 2D represented the required theoretical basis to establish a safe way to design and assess masonry vaulted structures [10]. The lower bound approach proposed in this paper requires a three-dimensional interpretation of Heyman's safe theorem, which is discussed in the following lines.

The addition of a third dimension to the safe or lower bound theorem means that a shell will be stable (globally) as long as a thrust network in equilibrium with the external forces can be determined within the limits of the structure, providing a lower-bound solution [18]. In the case of the extension of ELARM to shell structures, the limits would be the virtual boundaries, which would be the result of taking into account the contribution of the reinforcement and the limited compressive strength of the material.

The definition of the layout of forces in the primal grid given by the user determines the resulting thrust network and is therefore crucial regarding the outcome of the intended structural analysis or design. Since there is an infinite number of possible form diagrams, there are infinite possible thrust networks. Therefore, finding a thrust network that lies within the limits of the shell's virtual boundaries guarantees its global stability for the applied external forces, and not finding it does not mean that the shell is not stable, as the user is not able to check every possible form diagram. Furthermore, the possibility to create different reciprocal force diagrams from the primal grid increases even more the number of possible resulting thrust networks.

\section{Proposed method}

The three-dimensional approach to ELARM is presented as a lowerbound method for the structural design and analysis of reinforced masonry and/or concrete shells. Given the importance of the primal grid in the resulting thrust network, the user's appropriate choice of a series of force patterns to be tested becomes crucial for the outcome of the design or analysis process. A large structurally-informed scan of the possible primal grids will result in more optimised structures.

Although the extension of the method to 3D structures is not straightforward, a direct analogy can be established regarding some specific aspects when adding a third dimension. The thrust line becomes the thrust network, on whose vertices vertical loads can be applied. The lines defining the intrados and extrados in the 2D scheme correspond to surfaces in $3 \mathrm{D}$, just like the lines delimiting the $2 \mathrm{D}$ upper and lower virtual thicknesses correspond to the upper and lower fictitious surface boundaries in the three-dimensional model (Fig. 3).

In this approach to ELARM 3D, the geometry of the shell to assess or design is defined by its middle surface and the thicknesses of the tile vault and the concrete layer, $h_{\mathrm{tv}}$ and $h_{\mathrm{c}}$, from which the intrados and extrados surfaces are drawn.

The interpretation of stability regarding the characteristics of the shell's boundary conditions and the thrust network's support positions in relation to them is also analogous to the one in ELARM 2D regarding the position of the thrust line's end in relation to the boundary conditions [11 1]. In the case of pinned supports, the thrust network should land on the points where the shell is pinned. If the support consists of a contact surface, unable to take bending moments, the thrust network can pass through any point of the mentioned surface, which should be contained within the physical boundaries of the shell. Finally, in the case of fixed supports, the limits for the thrust network at the supports coincide with the virtual thickness. 


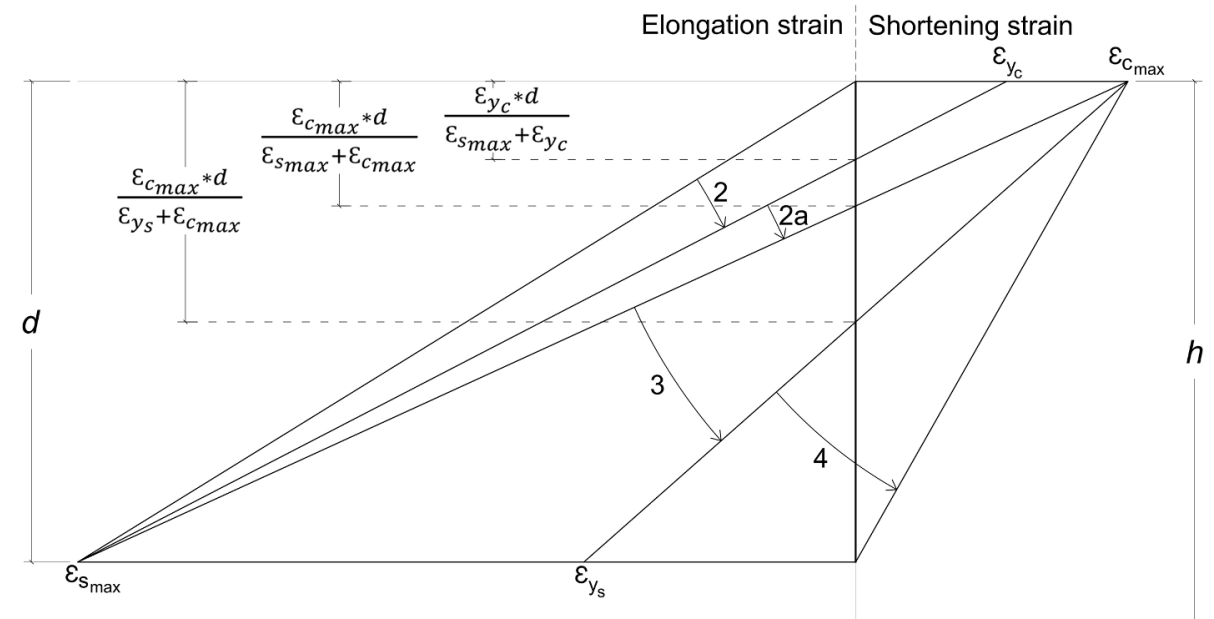

Fig. 4. The different strain domains that the cross-section state can be within.

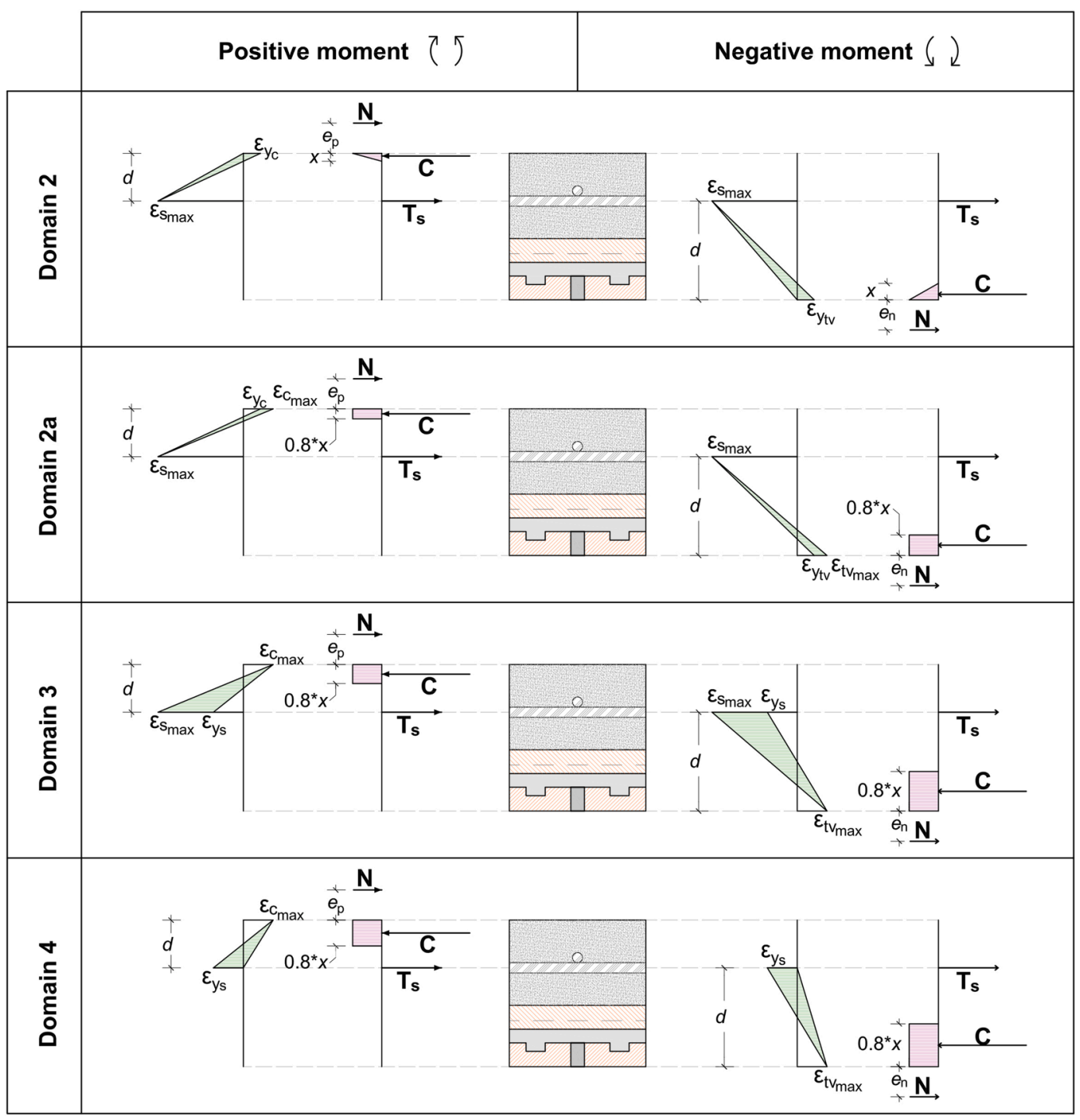

Fig. 5. Distribution of strains, stresses and forces in the different strain domains.

\subsection{Cross-sectional analysis: New virtual thickness}

The method adopted for the analysis of the cross section's bending ultimate limit state, presented in López López et al. (2019) [1], is based on the approach for members subjected to combined axial loading and bending moment described in Eurocode 2 [26] for reinforced concrete 


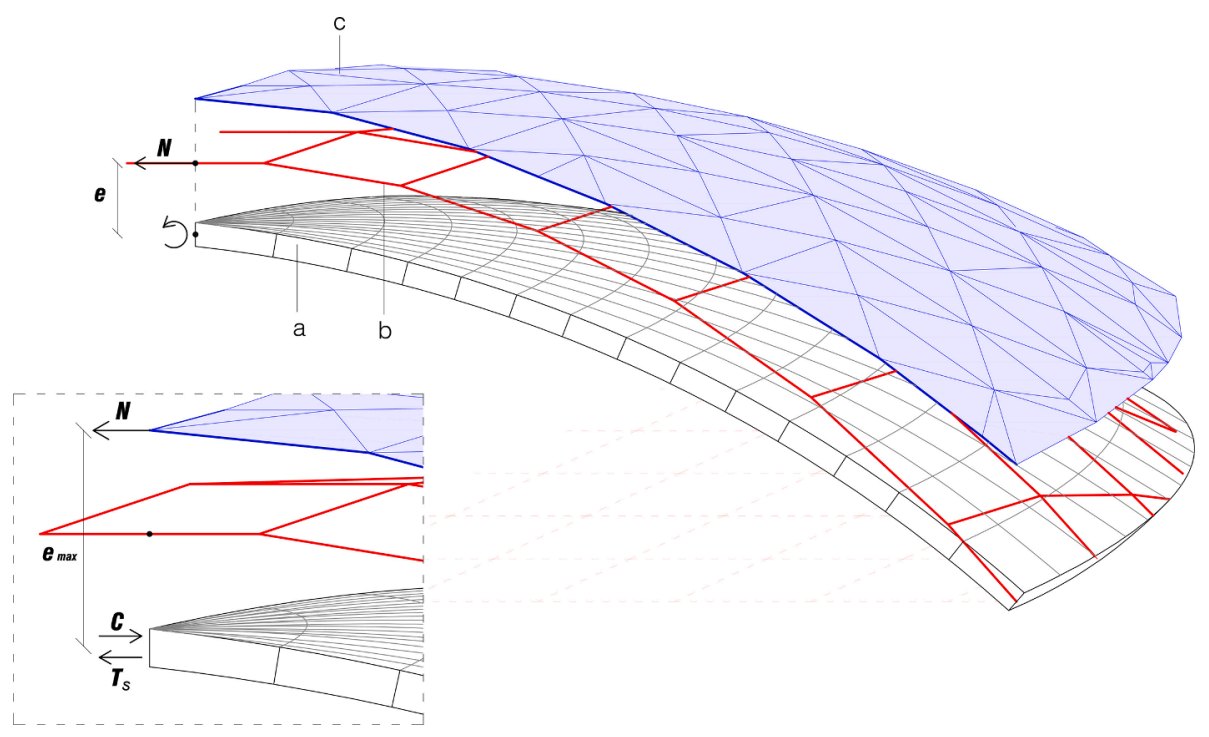

Fig. 6. Thrust network located outside of the shell's thickness creating a bending moment; a) reinforced masonry shell, b) thrust network, and c) upper virtual thickness. Lower left) schematic distribution of forces for the ultimate positive bending moment.

and Eurocode 6 [27] for reinforced masonry. The cross-section is analysed in bending at its ultimate limit state, meaning that either the steel, the concrete or the tile vault masonry have reached their ultimate strain, which is set to 0.01 for steel $\left(\varepsilon_{s_{\max }}\right)$ and 0.0035 for concrete $\left(\varepsilon_{c_{\max }}\right)$ or tile vault masonry $\left(\varepsilon_{t v_{\max }}\right)$ according to [26 27]. As described in [1], four possible strain domains for the cross-section at the ultimate limit state are considered. According to Fig. 4, the possible strain domains for the cross-section at this ultimate limit state are labelled 2, 2a, 3 and 4. Subdivision 2a in domain 2 is considered depending on whether the concrete or masonry have reached their yield limit. The identification of these selected domains is important, as each indicates a different stress-strain state of the materials and corresponds to a different system of equations to solve for the equilibrium of the cross-section. Domain 2 corresponds to failed steel and non-yielded concrete or masonry, whereas in domain 2a the concrete or masonry have reached their yield stress. Domain 3 corresponds to crushed concrete or masonry and yielded steel, while in domain 4 the steel has not reached its yield stress. The limits of the strain domains are determined by the position of the neutral axis, which is defined here by the distance of the most compressed fibre to the neutral axis $(x)$. From the deformation compatibility equations, the mentioned limits can be expressed as follows:

$0 \leq x_{2} \leq \frac{\varepsilon_{y_{c}} d}{\varepsilon_{s_{\max }}+\varepsilon_{y_{c}}} \leq x_{2_{a}} \leq \frac{\varepsilon_{c_{\max }} d}{\varepsilon_{s_{\max }}+\varepsilon_{c_{\max }}} \leq x_{3} \leq \frac{\varepsilon_{c_{\max }} d}{\varepsilon_{y_{s}}+\varepsilon_{c_{\max }}} \leq x_{4} \leq d$

where $x_{n}$ are the values of $\times$ in the $n$-th domain, $\varepsilon_{y_{s}}$ is the tensile yield strain of the steel and $\varepsilon_{y_{c}}$ is the assumed compressive yield strain of the concrete and $d$ is the effective depth of the section (i.e., the distance between the most compressed fibre in the section and the centroid of the reinforcement layer).

The assumed distribution of strains, stresses and forces in the crosssection for each strain domain can be seen in Fig. 5. The distance $\times$ of the neutral axis to the most compressed fibre at the ultimate limit state in bending for a given axial force, $N$, can be calculated from the equilibrium equations in each strain domain. A perfectly plastic bi-linear stress-strain relationship is considered for the reinforcement steel, whereas for the masonry and concrete, a linear stress-strain relation is applied in the elastic range and a rectangular stress block distribution in the plastic state [27].

The ratio between the ultimate moment and the axial force is equal to the maximum possible eccentricity, $e_{\max }$, which defines the virtual thickness. The ELARM 3D approach has specific ways to obtain the variables of the equations to assess the composite cross section in order

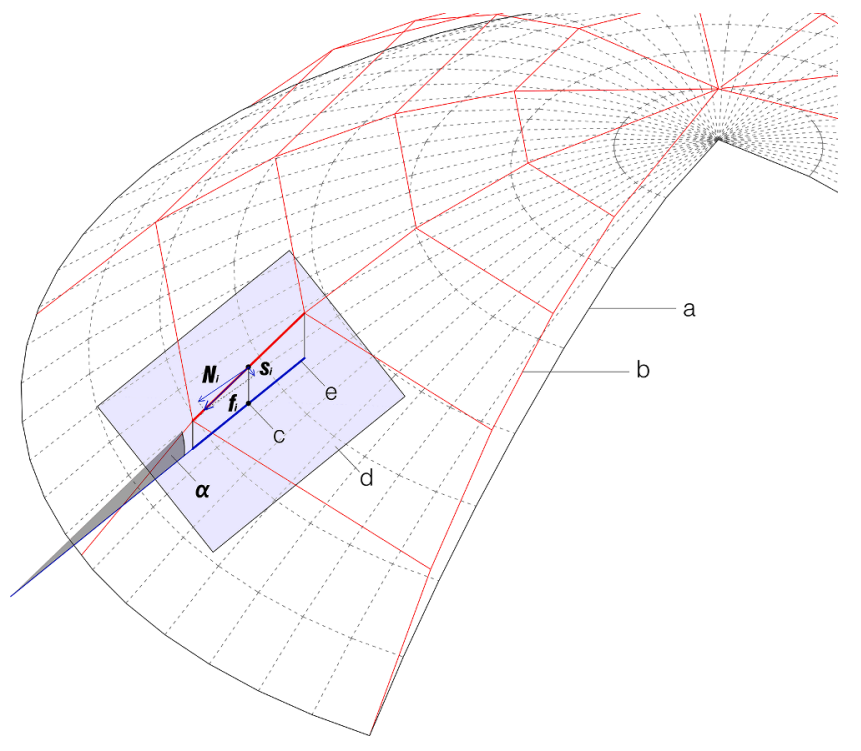

Fig. 7. Figure illustrating the way to obtain the values to compute $\mathrm{N}$ and $\mathrm{S}$ from the thrust network, a) shell's middle surface, b) thrust network, c) vertical projection of the analysed thrust network's edge's midpoint to the middle surface, d) plane tangent to the middle surface on the projection of the midpoint, e) vertical projection of the edge to the tangent plane.

to find the maximum positive and negative bending moments and determine the shell's virtual thickness. In the following equilibrium equation,

$C=N+T_{s}$

the variables are obtained as described in the next paragraphs. These variables are the axial force and the compressive and tensile forces acting on the cross section, $N, C$ and $T_{S}$ respectively (Fig. 6).

The thrust network is not only essential to guarantee the structure's global stability provided that it lies within the shell's virtual boundaries, but it also allows the extraction of the internal forces, $f$, on each edge of the network, required to obtain the axial and shear forces, $N$ and $S$ respectively, acting on the structure. These internal forces are extracted through TNA [17] when computing the thrust network's equilibrium, as mentioned in Section 2.1. 


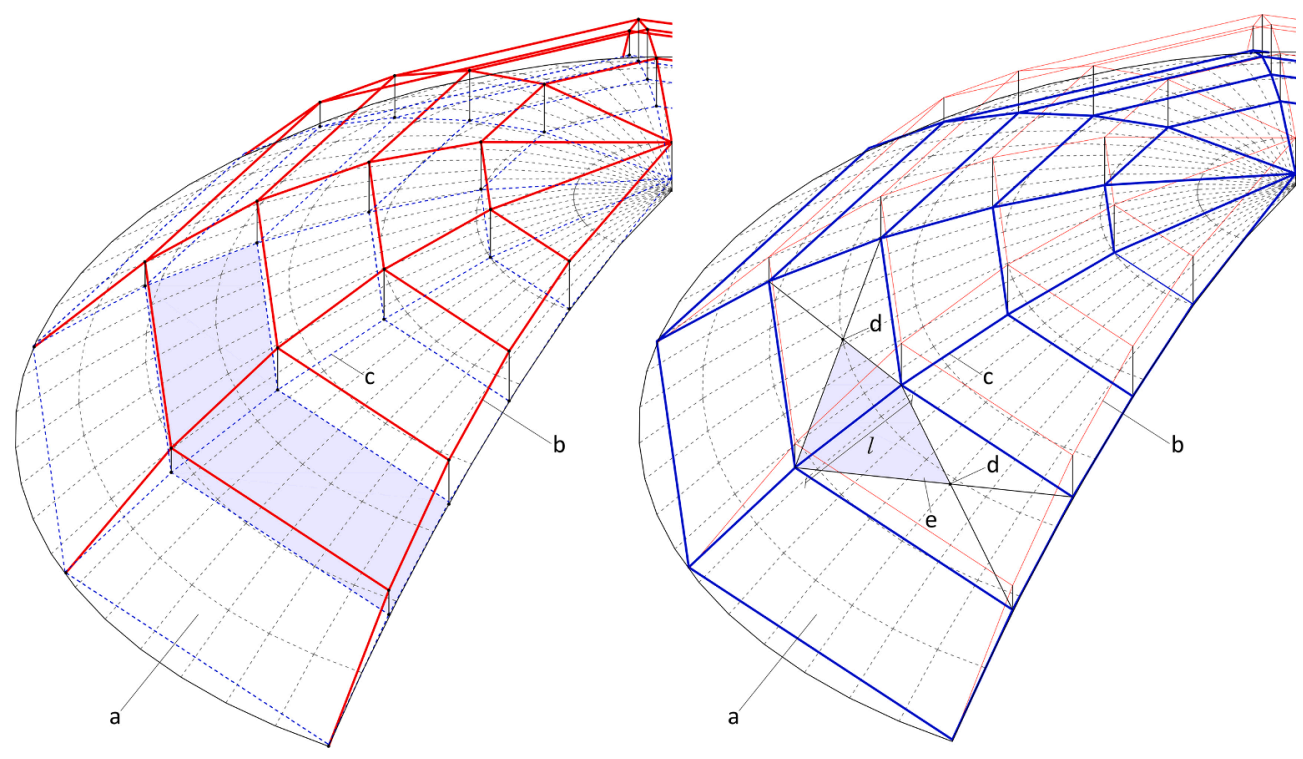

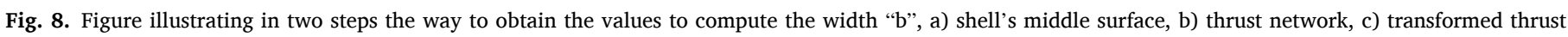

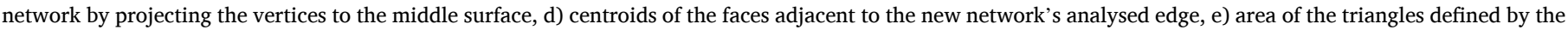
faces' centroids and the edge's start and end points.

The process to obtain the axial and shear forces is illustrated in Fig. 7. For each edge in the thrust network, its midpoint is vertically projected to the shell's middle surface. A plane tangent to that surface and containing the projected point is created. The edge is then vertically projected to the tangent plane. The angle, $\alpha$, of the edge with the line resulting from the projection is computed. The axial and shear forces, $N$ and $S$, can be obtained for each edge midpoint using the following equations respectively:

$N=f \cos \alpha$

$S=f \sin \alpha$

The cross section can be then checked against shear using the equations for reinforced concrete in clause 6.2.2 from Eurocode 2 [26]. The axial force is used during the cross-sectional analysis proposed in the ELARM 3D method to compute the new virtual thickness.

Considering the process to compute the axial force in each thrust network's edge midpoint and its vertical relation to the cross-section involved in the calculation, the shell is virtually enlarged also in the vertical direction to allow the checking of the stability by comparing each maximum eccentricity with the position of the related thrust network's edge midpoint.

The compression, $C$, experienced by either the concrete or the tile vault (positive or negative moment respectively) is computed via the following equations [26]:

$C=\frac{1}{2} x b E_{k} \varepsilon_{k}$

$C=0.8 x b f_{k}$

Equation 5 is applied in the case of considering the material on its elastic range, with a linear stress-strain relation (domain 2), whereas Equation (6) is applied when considering the material on its plastic range and a rectangular stress block distribution (domains 2a, 3 and 4). $f_{\mathrm{k}}$ is the compressive strength of the concrete or tile vault and $E_{\mathrm{k}}$ is the concrete's or tile vault's Young's Modulus. $\varepsilon_{\mathrm{k}}$ is the maximum compressive outer fibre strain, obtained from the strains' deformation compatibility equations (Fig. 5, green diagrams):

$\varepsilon_{k}=\frac{\varepsilon_{s_{\max }} x}{d-x}$
In both equations, Eq. 5 and Eq. (6), $b$ is the width assigned to compute the compressed area, whose method to be obtained is specific for the 3D extension of ELARM and is described in the following lines.

The virtual thickness is computed for the cross section at the supports and at the points corresponding to the vertical projection of each thrust network's edge midpoint to the shell's middle surface. For each of those spots where the virtual thickness is computed, the applied eccentric axial force, $N$, generating the bending moment, is extracted from the thrust network's corresponding edge, and the width, $b$, of the compressed block (concrete or tile vault) is also related to it. Fig. 8 illustrates the process to obtain it, which is based on the calculation of the tributary area of the edge and an average width to be applied at the mentioned specific points. The first step is to copy and transform the thrust network by vertically projecting each of its vertices to the shell's middle surface. For each edge of the new network, the centroid of its adjacent faces is found (only one face if the edge is at the boundaries). The areas of the triangles defined by the face's centroid and the edge's start and end points are computed. Afterwards, the addition of both areas is divided by the length of the edge. The described process to obtain the width, $b$, is valid for any kind of primal grid's force pattern and results in a conservative value.

The tensile forces at the reinforcement, $T_{\mathrm{s}}$, are obtained using also two different expressions, namely

$T_{s}=A_{s} E_{s} \varepsilon_{s}$

$T_{s}=A_{s} f_{s}$

These expressions correspond, respectively, to the case of the steel stresses in their elastic range (domain 4) and to the case of an ultimate bending moment leading to yielded steel (domains 2 , 2a and 3). $E_{\mathrm{s}}$ is the steel's Young's Modulus, $f_{\mathrm{s}}$ the reinforcement's tensile yield strength and $\varepsilon_{\mathrm{s}}$ its strain level, obtained from the strains' deformation compatibility equations (Fig. 5, green diagrams):

$\varepsilon_{s}=\frac{\varepsilon_{k_{\max }}(d-x)}{x}$

where $\varepsilon_{k_{\max }}$ is the ultimate strain of the concrete $\left(\varepsilon_{c_{\max }}\right)$ or the tile vault $\left(\varepsilon_{t v_{\max }}\right)$.

In both equations, Eq. (8) and Eq. (9), $A_{\mathrm{S}}$ is the effective steel reinforcement area regarding the direction of the corresponding thrust network's edge in relation to the reinforcement bars and the assigned 


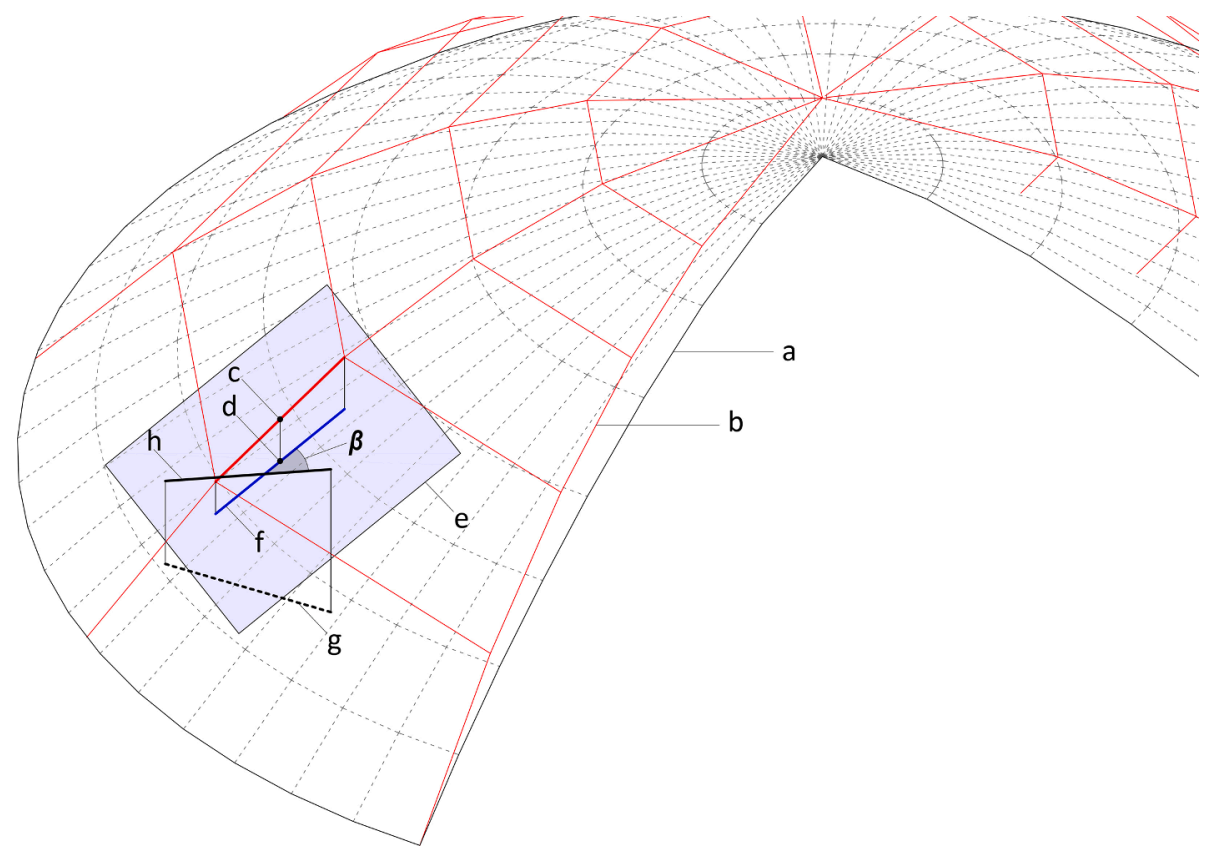

Fig. 9. Figure illustrating the way the angle $\beta$ is obtained, a) shell's middle surface, b) thrust network, c) midpoint of the analysed thrust network's edge, d) vertical projection of the edge's midpoint to the shell's middle surface, e) plane tangent to the middle surface on the projection of the midpoint, f) vertical projection of the edge to the tangent plane, $\mathrm{g}$ ) direction of the reinforcement in the horizontal plane, and $\mathrm{h}$ ) projection of the reinforcement's direction to the tangent plane.

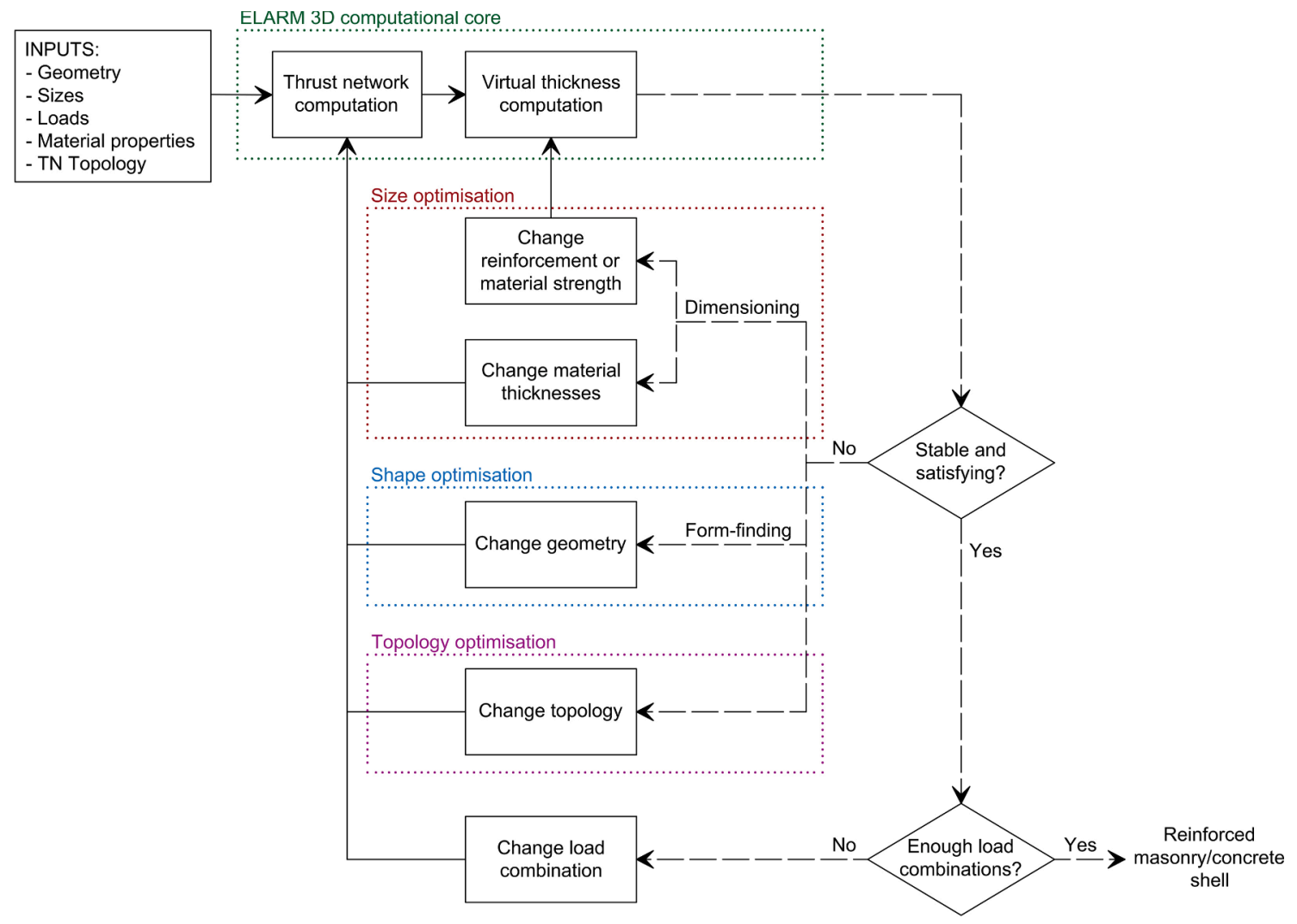

Fig. 10. Flow diagram of the computational approach.

width $(b)$. Different reinforcement configurations can be applied in different areas of the shell considering spots that might need a higher amount of reinforcement. The addition of the effective steel areas corresponding to the two different reinforcement directions results in the total area, $A_{s}$. For each direction, the effective area, $A_{s_{d}}$, can be expressed as follows:

$A_{s_{d}}=A_{s_{r}} \cos \beta \frac{1}{\frac{L}{\operatorname{sen}(90-\beta)}} b=A_{s_{r}} \cos ^{2} \beta \frac{b}{\mathrm{~L}}$

where $A_{s_{r}}$ is the area of a single steel reinforcement bar, $L$ is the spacing 
between rebars and $\beta$ is the angle obtained as described in the following lines and shown in Fig. 9. For each virtual thickness computation, this angle is obtained from the projection of the corresponding thrust network edge and the reinforcement direction to a plane that is tangent to the shell's middle surface and contains the point that results from the vertical projection of the corresponding thrust network's edge midpoint to the mentioned middle surface (Fig. 9). In Eq. 11, $A_{s_{r}} \cos \beta$ corresponds to the effective steel area of a single reinforcement bar, whereas $\cos \beta \frac{b}{\mathrm{~L}}$ is the number of bars in the corresponding reinforcement direction contained in the width, $b$, of the cross section.

\section{Computational implementation}

A computational implementation of the proposed method has been created in the Python language, making use of COMPAS [28], an opensource, Python-based computational framework for collaboration and research in architecture, structural engineering and digital fabrication. Specifically, the so-called COMPAS TNA package has been used to generate and manipulate the thrust network and the form and force diagrams. The software Rhinoceros and plugin Grasshopper are used to visualise the results and to introduce and modify input parameters. The developed tool provides immediate graphical and intuitive results.

The flow diagram in Fig. 10 illustrates the process of the design and/ or structural analysis of a composite reinforced masonry shell with this tool. The first step is to introduce the inputs to define the geometry, the cross section, the loads, the material properties and the thrust network topology or force layout. Then the force diagram, the thrust network and the virtual thickness are computed and drawn together with the shell's intrados and extrados. The program will also indicate if any point of the thrust network lies outside the computed virtual boundaries, in which case, the inputs can be modified through a size, shape or thrust network optimisation. Similarly as in the two-dimensional version [1], the size optimisation entails the modification of the reinforcement's position or quantities, the materials strength or the thicknesses of the different material layers, whereas the shape optimisation involves manipulating the shell's geometry to be able to contain the thrust network within its virtual thickness' limits. The thrust network optimisation is specific from ELARM 3D and is carried out by modifying the topology of the form diagram, i.e., the forces layout of the primal grid, or by adjusting the distribution of forces in the reciprocal force diagram to achieve a convenient thrust network [18 17]. While carrying out these processes, the thrust network and the virtual thickness are automatically recomputed, providing immediate structural feedback. Once a stable and satisfying shell is achieved, further load combinations can be checked if needed.

The reinforcement optimisation requires the possibility of assigning different positions and quantities to the rebars along the shell. The computational implementation allows the definition in plan of areas with different reinforcement quantities and directions. The user defines these areas by drawing a polygon in plan and assigning reinforcement values. The algorithm detects the primal grid edges midpoints inside each polygon and associates the corresponding values.

The outcome of the design or lower-bound analysis using the proposed approach is sensitive to the orientation of the reinforcement bars in relation to the direction of each thrust network's edge. As explained in Section 3.1, the total effective area of steel reinforcement, $A_{\mathrm{s}}$, considered for each edge of the thrust network is dependent on the angle $\beta$ (Fig. 9). According to Eq. 11, a higher value of $\cos \beta$ increases the effective steel reinforcement area assigned to the thrust network's edge. The maximum area would be then achieved for a value of $\beta$ equal to 0 . An alignment of
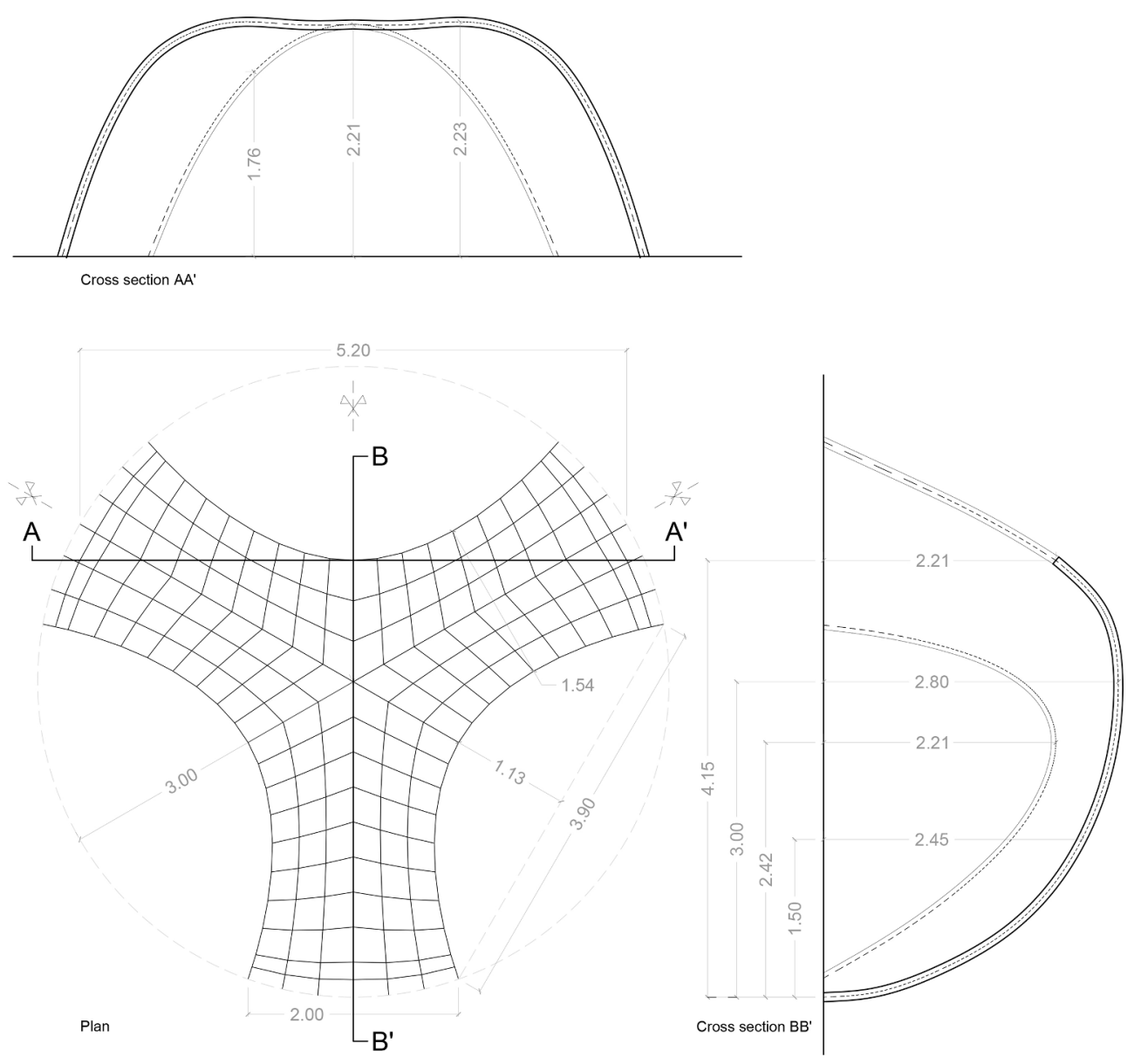

Fig. 11. Geometry of the shell and the primal grid. Dimensions correspond to the shell's middle surface. 

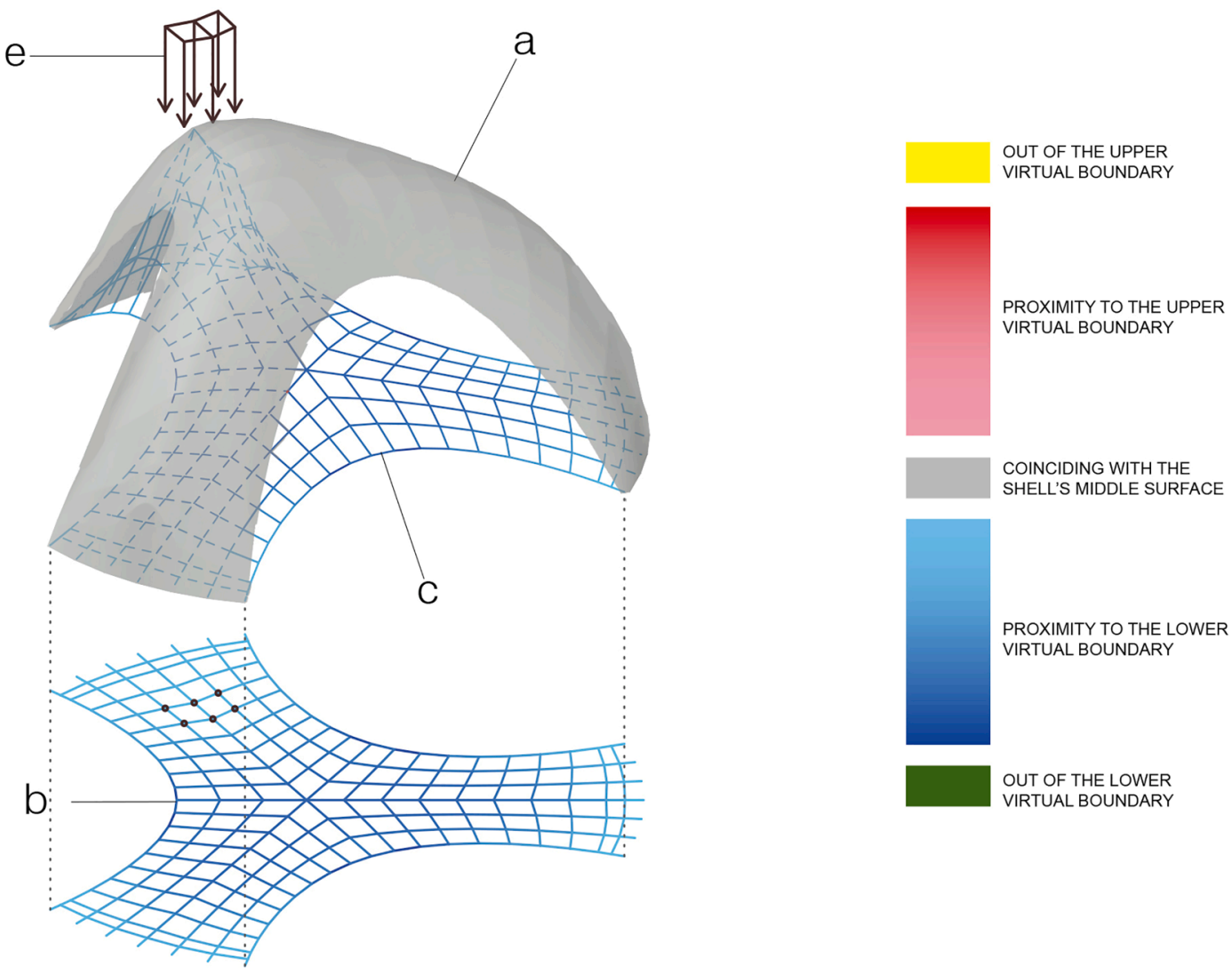

REINFORCEMENT ON THE EXTRADOS

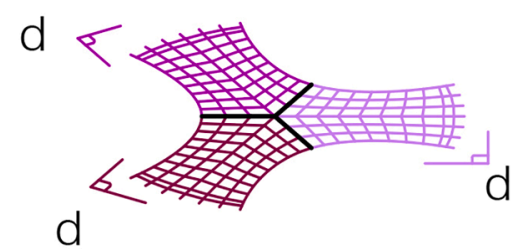

Fig. 12. Application of ELARM 3D to a free-form composite shell with reinforcement at the extrados. a) shell, b) primal grid, c) thrust network, d) steel reinforcement bar's direction, and e) load.

the primal grid's edges with the reinforcement directions is therefore recommended in order to optimise the assigned effective steel reinforcement area.

In the search for meaningful and appropriate force distributions, the layout of a primal grid might not correspond with a logical arrangement of reinforcement bars regarding construction ease and economy. The designer should then consider the checking of different reinforcement direction solutions or different thrust networks for an optimal (easy) reinforcement direction and the comparison of the resulting virtual thicknesses.

As mentioned in Section 2.1, the definition of the specific primal grid determines the results of any application of TNA, and therefore also the outcome of the design or analysis using ELARM 3D. Research on clever ways and strategies to produce appropriate patterns meeting specific requirements and conditions still needs to be conducted to achieve properly optimised structures avoiding the process of trying different primal grids. Research by Oval et al. (2017, 2018 and 2019) [29 30 31] addresses this topic and could be incorporated to ELARM 3D, as it was implemented using the same open-source computational framework COMPAS [28].

Further research on the optimisation of the reinforcement solutions can be addressed from two different perspectives (or the combination of both of them): 1) including the variable of the reinforcement in the research on the optimisation of appropriate patterns mentioned in the previous paragraph, and 2) without modifying the primal grid, automating the check of different options for reinforcement directions and the comparison of the resulting virtual thicknesses to provide the user with the most convenient reinforcement layout.

\section{Applications}

This section is devoted to the presentation of applications of the computational tool developed for the implementation of the current approach to ELARM 3D. The description of different examples with different material properties and geometries shows the potential of the tool and 3D method. These examples include reinforcement optimisation, a form-finding process and a non-compression-only shell.

The visualization strategy for the production of the figures in this section is explained in the following lines. The results are displayed on the thrust network and on the primal grid by applying a range of colours to the edges according to the position of the corresponding thrust network's edge midpoint in relation to the virtual thickness and the shell's 

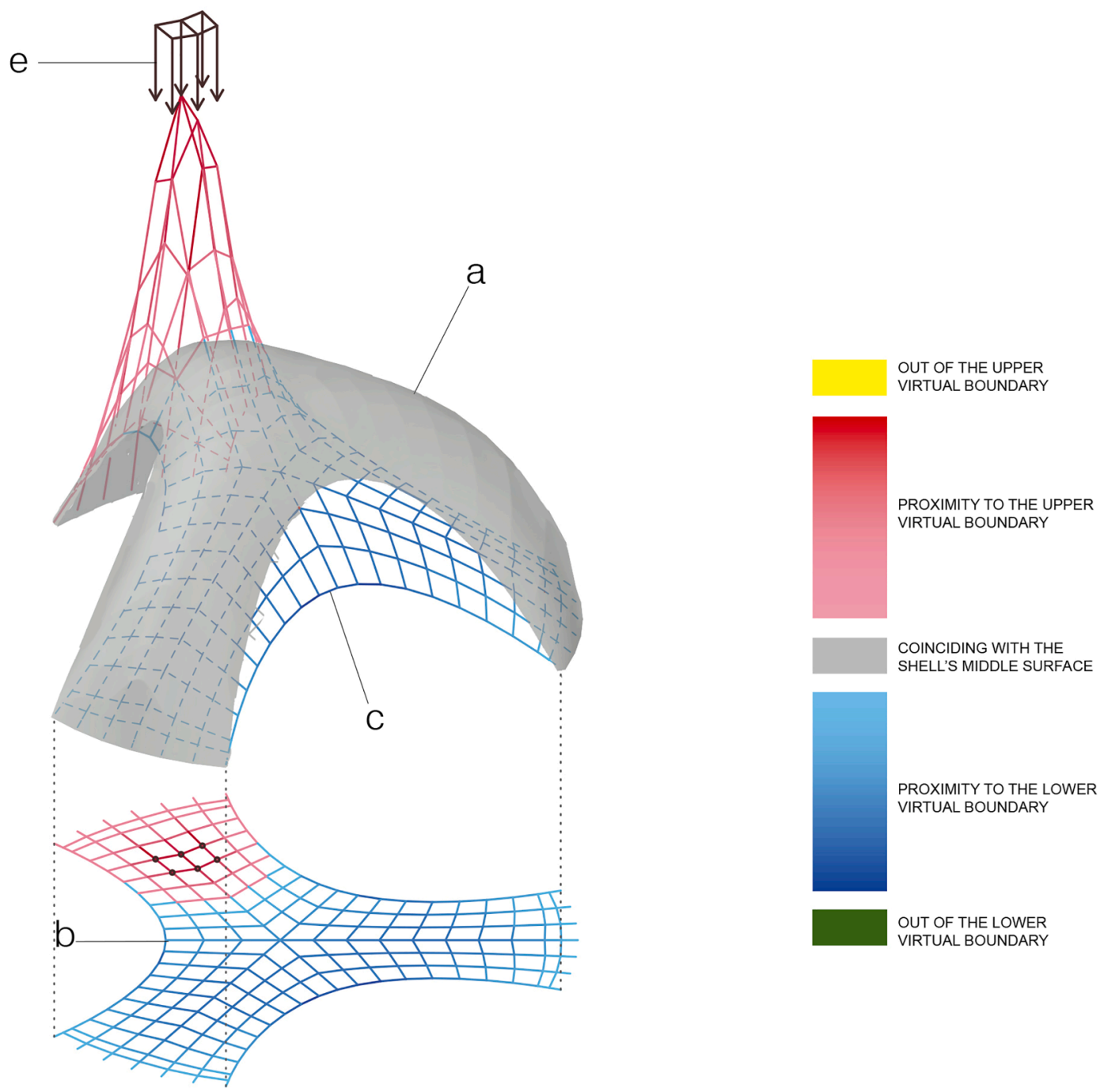

REINFORCEMENT AT CENTRAL LEVEL

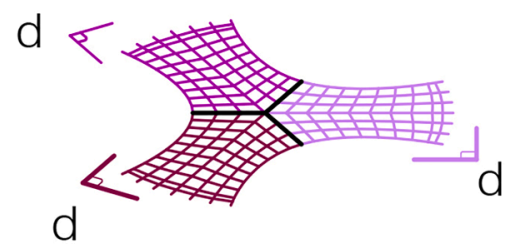

Fig. 13. Application of ELARM 3D to a free-form composite shell. a) shell, b) primal grid, c) thrust network, d) steel reinforcement bar's direction, and e) load.

middle surface, i.e., highlighting the ratio between the eccentricity of each edge's axial force and the corresponding maximum eccentricity. The edges outside the virtual thickness from above are coloured yellow, while those outside the virtual thickness from below are coloured green. For the edges within the virtual boundaries, i.e., complying with the stability requirement, a distinction is made between the ones above or below the shell's middle surface. A red gradient is used for the edges above and a blue gradient for the edges below. A darker red or blue colour means more relative proximity to the upper or lower virtual boundaries respectively. Finally, the colour grey means that the thrust network's edge's midpoint is located in the shell's middle surface. A legend is included in each figure.

\subsection{Reinforcement optimisation}

The proposed approach to ELARM 3D allows the placement of the required reinforcement in the desired directions in specific regions of the vault's surface. Position and amount of reinforcement can thus be adjusted together with the thickness of the shell to carry out a cross section optimisation, while accounting for different load combinations. Note that it is a reinforcement optimisation of the shell for the chosen primal grid. Unless a topology optimisation of the force diagram is carried out, since not every thrust network can be tested, there might be other form and force patterns providing better results (as described in Section 2.2).

An example of this reinforcement optimisation carried out with the current approach to ELARM 3D is illustrated in Fig. 11, Fig. 12, Fig. 13 

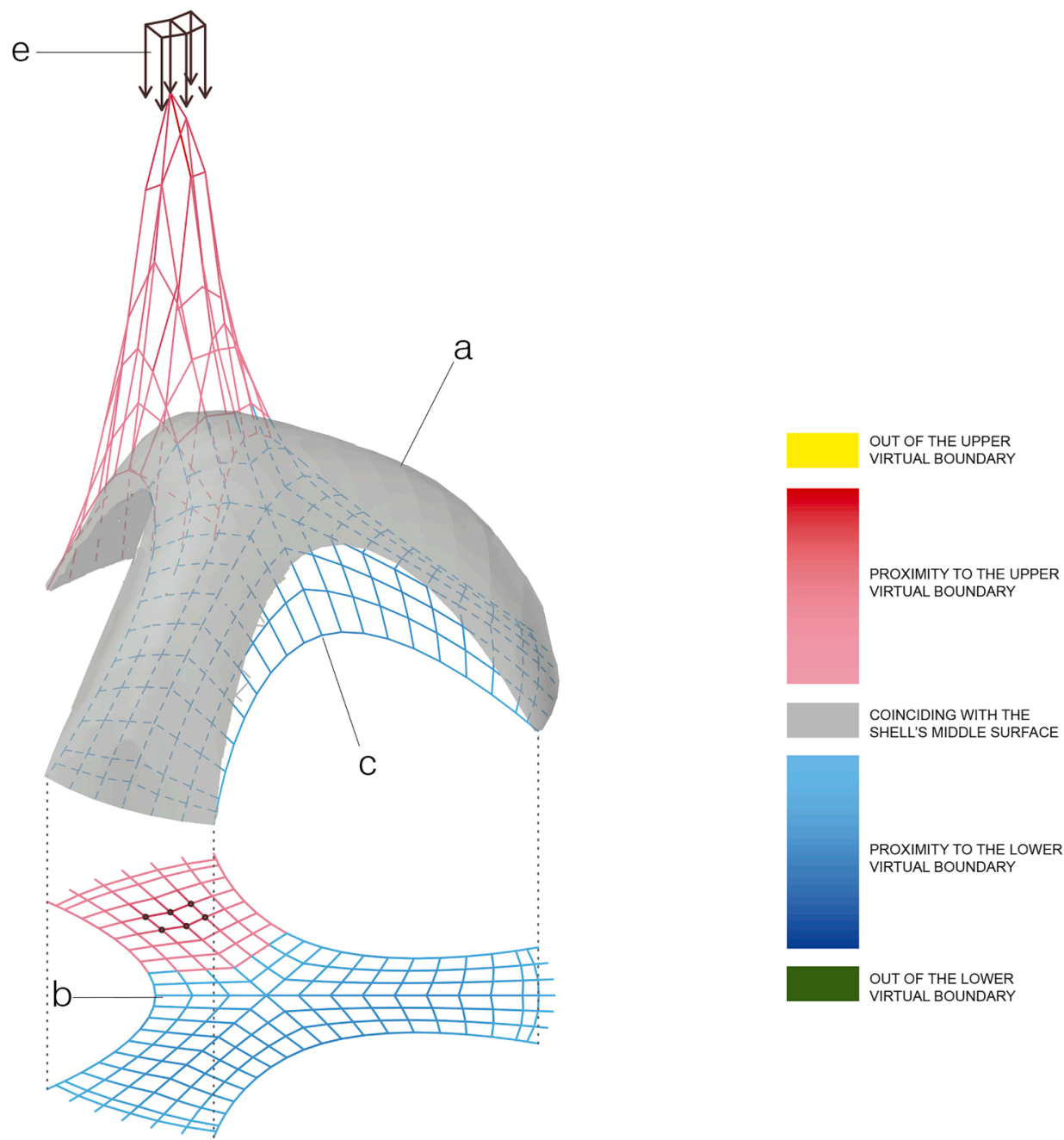

REINFORCEMENT ON THE INTRADOS

REINFORCEMENT ON THE EXTRADOS
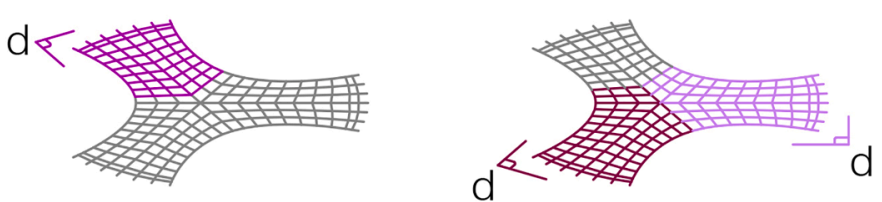

Fig. 14. Application of ELARM 3D to a free-form composite shell with reinforcement at the extrados and intrados. a) shell, b) primal grid, c) thrust network, d) steel reinforcement bar's direction, and e) load.

and Fig. 14. The example features a free-form composite shell with three supports, a span of $5.2 \mathrm{~m}$ (measured as the distance between two centres of two supports) and a height of $2.8 \mathrm{~m}$. The geometry of the studied shell and that of its corresponding primal grid are detailed in Fig. 11. The studied composite structure includes a $36-\mathrm{mm}$-thick tile vault and a thin concrete layer with a thickness of $50 \mathrm{~mm}$. The compressive strength of the tile vault and the concrete are taken as $13 \mathrm{~N} / \mathrm{mm}^{2}$ and $22 \mathrm{~N} / \mathrm{mm}^{2}$ respectively, with densities of $2000 \mathrm{~kg} / \mathrm{m}^{3}$ for the tile vault and 2400 $\mathrm{kg} / \mathrm{m}^{3}$ for the concrete. The steel's yield tensile strength for the reinforcement is $580 \mathrm{~N} / \mathrm{mm}^{2}$. A total load of $2 \mathrm{kN}$ is applied as loads of $0 . \widehat{3} \mathrm{kN}$ on 6 vertices of the thrust network as shown in Fig. 12, Fig. 13 and Fig. 14. Maintaining the geometry, thickness, primal grid, loads, material properties and 6-mm-thick rebars, the analysis consisted of adjusting the thrust network's height and the spacing and the position of the rebars to achieve an optimised structure regarding the reinforcement and for the chosen primal grid.

Taking advantage of the options that the implementation of ELARM $3 \mathrm{D}$ offers to define the direction, amount and position of reinforcement in different regions of the shell, three different regions of reinforcement are set seeking an orientation similar to the one of the primal grid in each support (Fig. 12, down).

Fig. 12 illustrates a hypothesis in which reinforcement can only be applied on the extrados; for example, when strengthening an existing structure. In this case, the reinforcement will only provide additional lower virtual thickness, and the thrust network is therefore adjusted to not surpass the extrados of the shell. A stable structure is guaranteed applying a reinforcement equivalent to 6-mm-thick steel rebars at 70 $\mathrm{mm}$ spacing in both directions. Considering that the load could be applied on any of the three supports, the same amount of reinforcement is equally applied over the vault.

In the analysis illustrated in Fig. 13, the reinforcement is placed at a central level of the concrete layer's thickness and provides the shell with bending capacity both for positive and negative moments. ELARM 3D computes therefore an upper and a lower virtual thickness and the thrust network's height is adjusted accordingly. A spacing of $150 \mathrm{~mm}$ in both directions is needed to guarantee a stable structure, resulting in a 

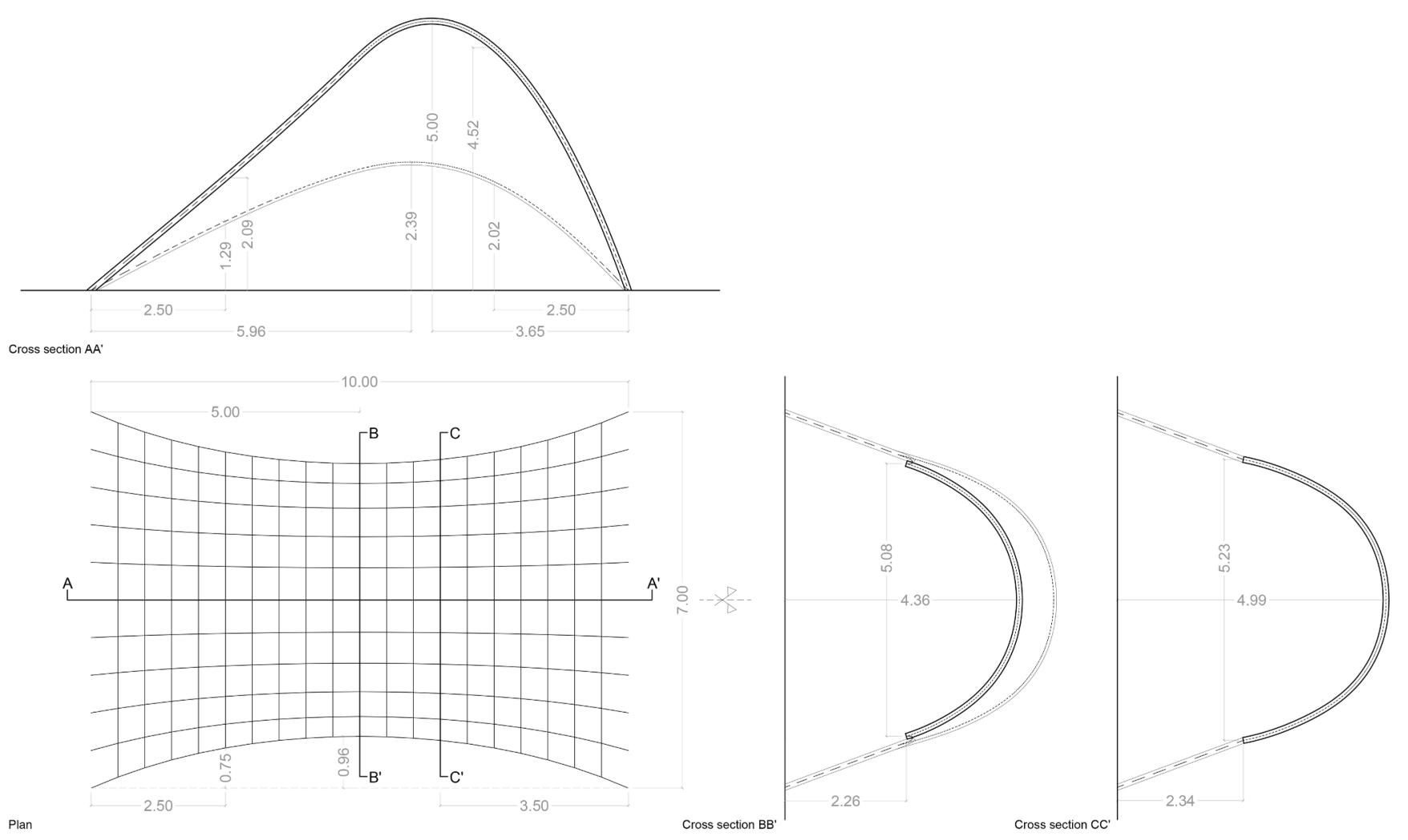

Fig. 15. Geometry of the shell and the primal grid. Dimensions correspond to the shell's middle surface.

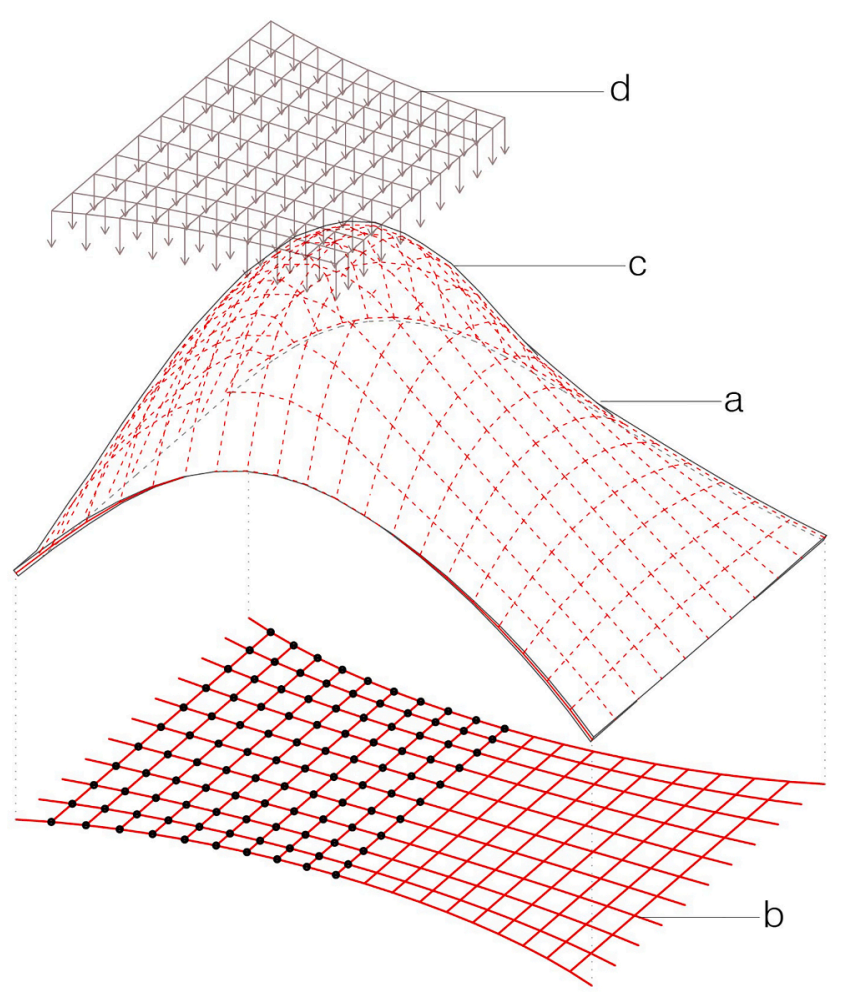

Fig. 16. Form-finding using ELARM 3D. a) shell, b) primal grid, c) thrust network, and d) load.

significant reduction of the reinforcement compared to the previous analysis of the same dome. The possibility to adjust the position of the reinforcement within the cross section's thickness has allowed, in this case, a reduction of $53.25 \%$ of the steel amount. Furthermore, a higher thrust network has been achieved, reducing the horizontal thrust at the supports.

A last configuration of the reinforcement is shown in Fig. 14. In this case, the load is considered to be permanently applied on the defined spot of that specific support (not in any of the supports). The reinforcement is optimised by placing it at the intrados or the extrados where needed in order to provide upper or lower virtual thickness respectively. The spacing of the reinforcement placed at the intrados is $170 \mathrm{~mm}$ in both directions, while that of the one placed at the extrados is $190 \mathrm{~mm}$ also in both directions. Considering as constant inputs the material properties, the shell's geometry, the sizes and the thrust network's topology and having permanent loads, the optimization process consisted of adjusting the thrust network's height and the reinforcement, which is placed at the intrados or the extrados to maximise the shell's bending capacity for positive or negative moments, respectively. In this case, the reinforcement quantities have been reduced to $38.28 \%$ of the steel amount computed in the first analysis (Fig. 12).

\subsection{Form-finding}

This approach to ELARM 3D and its computational implementation allow the optimisation of the shell's shape regarding a defined loading condition. This is achieved by modifying the geometrical inputs of the structure to make geometry and thrust network match as much as other design constraints would allow.

This feature is illustrated with the example in Fig. 15, Fig. 16 and Fig. 17. The presented shell has two parallel, linear supports, a span of $10 \mathrm{~m}$, a width ranging from 5 to $7 \mathrm{~m}$, a height of $5 \mathrm{~m}$ and its cross section is composed of a 59-mm-thick tile vault and a 50-mm-thick reinforced concrete layer. The geometry of the studied shell and that of its corresponding primal grid are detailed in Fig. 15. The compressive strength of the tile vault and the concrete are taken as $12 \mathrm{~N} / \mathrm{mm}^{2}$ and $25 \mathrm{~N} / \mathrm{mm}^{2}$ respectively, with densities of $2000 \mathrm{~kg} / \mathrm{m}^{3}$ for the tile vault and 2400 $\mathrm{kg} / \mathrm{m}^{3}$ for the concrete. The steel's yield tensile strength for the 


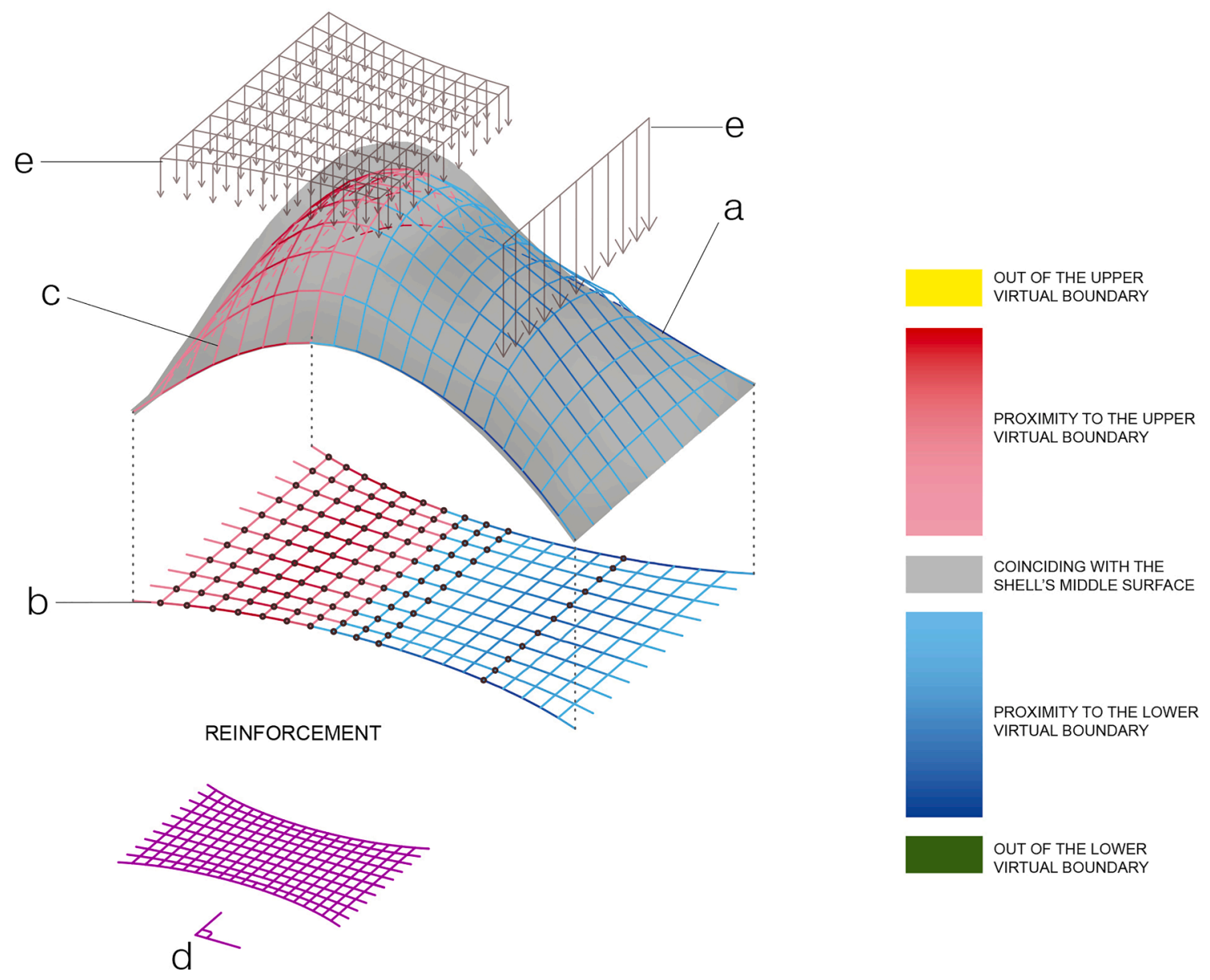

Fig. 17. Application of ELARM 3D to a form-found shape with an additional load. a) shell, b) primal grid, c) thrust network, d) steel reinforcement bar's direction, and e) loads.

reinforcement is $500 \mathrm{~N} / \mathrm{mm}^{2}$. A constant, predominant and permanent distributed load of $3.5 \mathrm{kN} / \mathrm{m}^{2}$ is applied to half of the shell (Fig. 16). The input shell's geometry is then modified and adjusted such that the generated thrust network fits within its thickness, achieving a formfound shape that would not need reinforcement provided that the mentioned load is permanent and the only one applied. In the formfinding process, the height of the thrust network can also be modified to achieve the desired shape.

Further load combinations may modify the thrust network such that parts of it would not stay within the thickness of the shell, requiring therefore reinforcement. Fig. 17 shows the analysis including an additional linear load of $4 \mathrm{kN} / \mathrm{m}$ along a width of $5.5 \mathrm{~m}(22 \mathrm{kN}$ in total), applied on the opposite side of the previously mentioned distributed load. The reinforcement, placed inside the concrete layer at $40 \mathrm{~mm}$ from the shell's top surface, consists of 6-mm-thick rebars at $200 \mathrm{~mm}$ in the transversal direction and 8-mm-thick rebars at $90 \mathrm{~mm}$ in the longitudinal direction. With this example, further flexibility of the reinforcement options is shown, applying different rebar diameters and spacing for each direction of reinforcement. The thrust network's edges in the longitudinal direction feature higher axial forces than those in the transversal direction. Therefore, having reinforcement directions coinciding or similar to those of the thrust network's edges, the steel amount on the transversal direction can be considerably smaller, representing only the $45.32 \%$ of the steel amount on the longitudinal direction.

\subsection{Beyond funicular geometry}

This section presents the use of ELARM's algorithms and computational implementation towards the design and assessment of free-form, composite shell structures with shapes such that, under self-weight, a thrust network cannot be contained within their thickness. Fig. 18, Fig. 19, Fig. 20 and Fig. 21 show an example with two different reinforcement configurations. The studied structure (Fig. 19, left) is a nonfunicular, free-form, composite shell with a tile vault thickness of 36 $\mathrm{mm}$ and a concrete layer of $50 \mathrm{~mm}$. The shell has two parallel, linear supports, a span of $10 \mathrm{~m}$, a width ranging from 4.3 to $7 \mathrm{~m}$, a maximum height of $3.35 \mathrm{~m}$ and no external forces applied. The geometry of the studied shell and that of its corresponding primal grid are detailed in Fig. 18. The material properties in terms of strength and density are the same as in the previous example in Section 5.2.

Given that the shell is not a compression-only structure, no thrust network fits within the real thickness of the shell. As a first attempt, a thrust network with a similar maximum distance to the extrados and the intrados is chosen (Fig. 19, right). As a result, the thrust network lies mostly outside the physical thickness of the shell, either surpassing the upper or the lower limits, therefore requiring reinforcement in the entire structure. This reinforcement is placed at a central level of the concrete layer's thickness and consists of an area of steel equal to $76 \mathrm{~mm}^{2}$ per meter in both directions, which is equivalent to 5-mm-thick steel rebars at $250 \mathrm{~mm}$. The result of the analysis with ELARM 3D is shown in Fig. 20.

Reinforcement can be optimised, as a different position of the thrust network allows a different reinforcement's configuration. The thrust network in Fig. 21 avoids reinforcement in parts of the shell by following the middle surface of the cross section to the extent possible. In the central part of the shell, due to its shape, the thrust network exceeds the physical upper boundary. Therefore, bottom level reinforcement has to be supplied to virtually extend the thickness of the shell upwards 


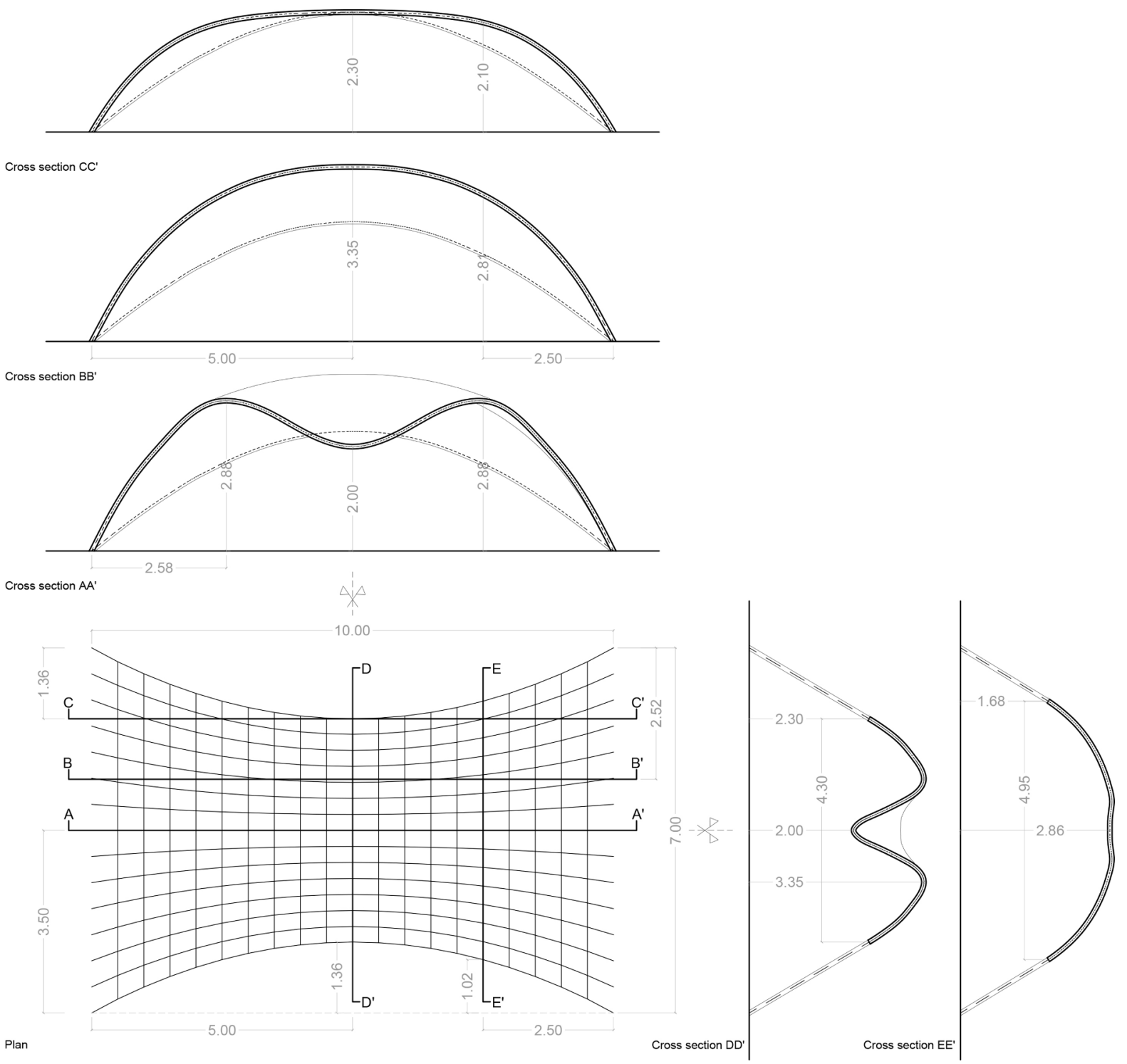

Fig. 18. Geometry of the shell and the primal grid. Dimensions correspond to the shell's middle surface.
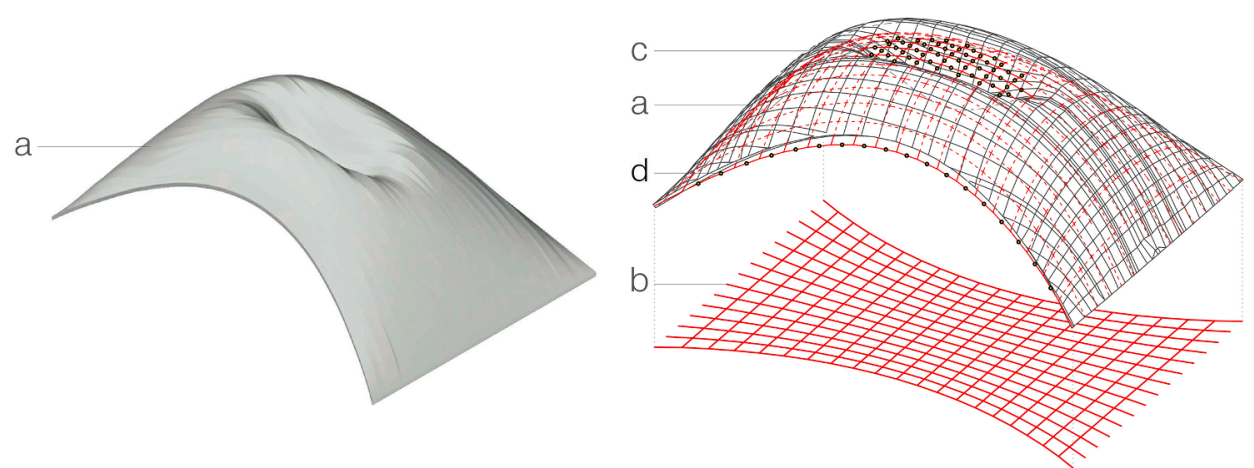

Fig. 19. Application of ELARM 3D to a non-compression-only shell. a) shell, b) primal grid, c) thrust network, and d) points of the thrust network out of the shell's real boundaries.

(Fig. 21, right). The reinforcement is placed at the intrados to maximise the shell's bending capacity for positive moments. A reinforcement of steel equal to $12 \mathrm{~mm}^{2}$ per meter in both directions was introduced in the model and was enough to keep the thrust network within the new virtual boundaries. The possibility to adjust the thrust network's height, the amount, quantities and direction of the reinforcement bars together with their position both within the shell's surface and within its thickness allows a significant reduction of the steel's requirement. 


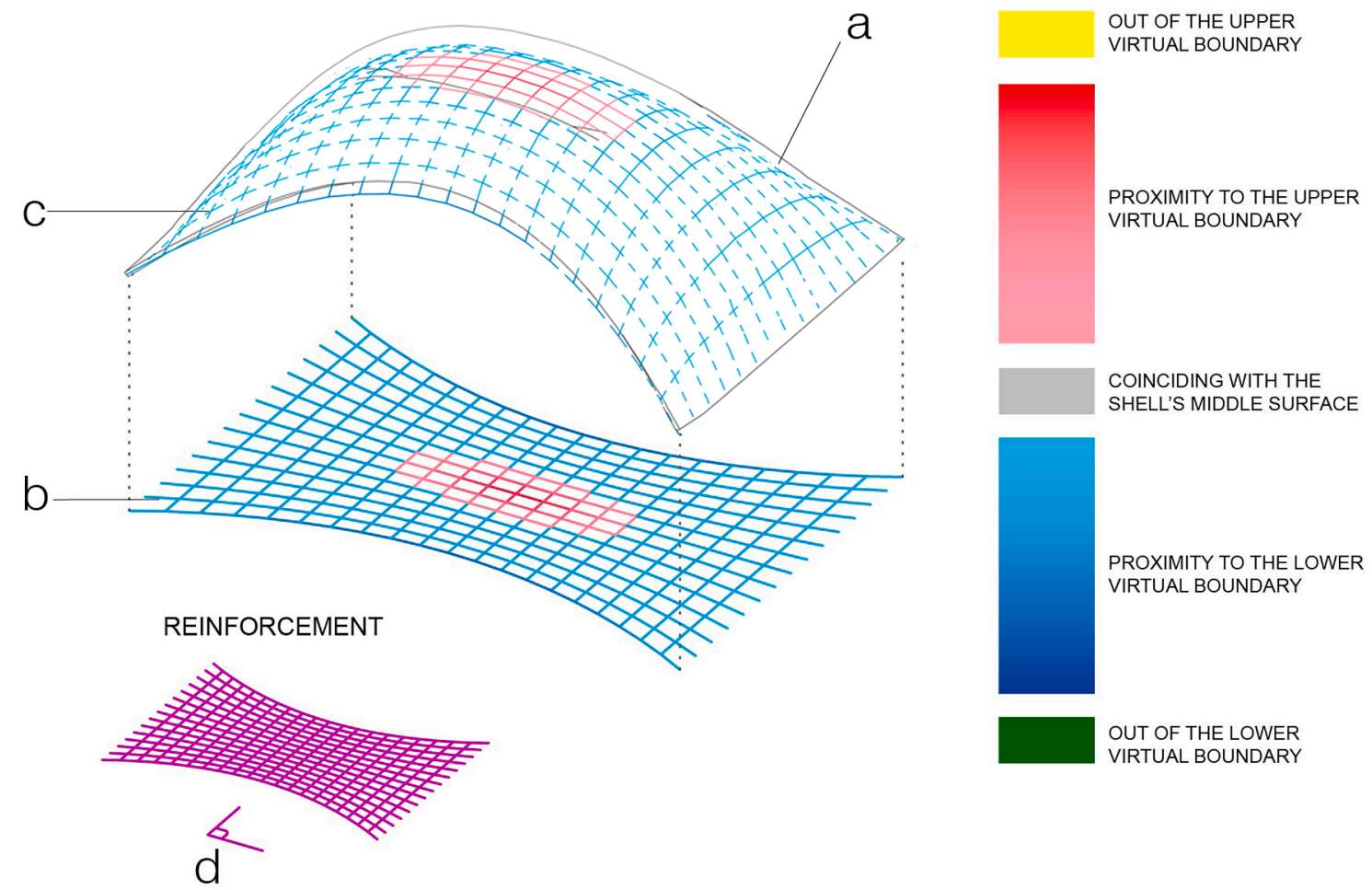

Fig. 20. Application of ELARM 3D to a non-compression-only shell. a) shell, b) primal grid, c) thrust network, and d) steel reinforcement bar's direction.
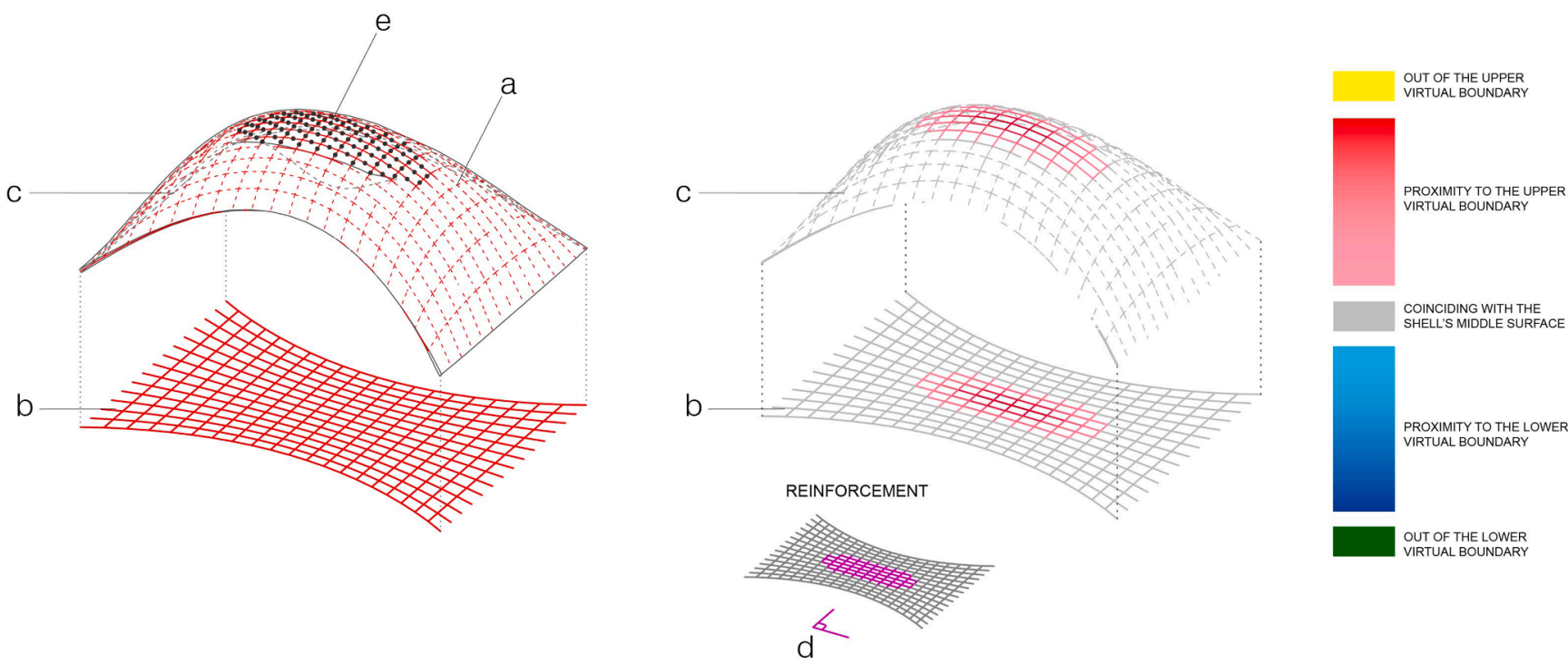

Fig. 21. Different reinforcement configuration for the non-compression-only shell. a) shell, b) primal grid, c) thrust network, d) steel reinforcement bar's direction, and e) points of the thrust network out of the shell's thickness.

\section{Conclusions}

The Extended Limit Analysis of Reinforced Masonry (ELARM) is a structural design and analysis method for singly-curved, reinforced masonry, concrete or composite, vaulted structures [1]. Although it is based on limit analysis [10], it takes into account the tensile capacity of the reinforcement and the compressive strength of the masonry and concrete.

An approach to the extension of ELARM to 3D structures has been presented in this paper. It is based on Thrust Network Analysis (TNA) [13 12] and provides lower-bound solutions for reinforced masonry and/or concrete shells. While different approaches to the limit analysis of $2 \mathrm{D}$ reinforced concrete or masonry arches can be found in the literature [ $\left.\begin{array}{lllll}11 & 12 & 13 & 14 & 15\end{array}\right]$, the novelty of ELARM 3D consists in the application of such approach to doubly-curved, fully-3D shell structures.

The leap from 2D to 3D has required the development of strategies to define and obtain the variables included in the equilibrium equations, such as the axial force and the compressive and tensile forces acting on the cross section, which in turn involve the definition of the width assigned to compute the compressed area, $b$, and the effective steel reinforcement area corresponding to each thrust network's edge, $A_{\mathrm{s}}$.

The computational implementation in $3 \mathrm{D}$ has been possible thanks to the combination of the ELARM's algorithms with TNA using the opensource, computational framework COMPAS [28]. The software 
Rhinoceros and plugin Grasshopper have been used to visualise the results and to introduce and modify input parameters. This setup results in an interactive and user-friendly tool offering responsive, structurallyinformed feedback. Seeking to show its potential, Section 5 described examples of its application including a shell's reinforcement optimisation, a form-finding case and the application to a non-compression-only structure.

\section{Declaration of Competing Interest}

The authors declare that they have no known competing financial interests or personal relationships that could have appeared to influence the work reported in this paper.

\section{Acknowledgements}

This work was supported by the Swiss National Science Foundation (SNSF, project number P2EZP2_181591).

\section{References}

[1] López López D, Roca P, Liew A, Van Mele T, Block P. Tile vaults as integrated formwork for reinforced concrete: Construction, experimental testing and a method for the design and analysis of two-dimensional structures. Eng Struct 2019;188: 233-48. https://doi.org/10.1016/j.engstruct.2019.03.034.

[2] La HS. mecánica de las bóvedas tabicadas en su contexto histórico, con particular atención a la contribución de los Guastavino. In: Huerta S, editor. Las bóvedas de Guastavino en América. Madrid: CEHOPU, Instituto Juan Herrera; 2001. p. 87-112.

[3] Block P, DeJong M, Davis L, Ochsendorf J. Tile vaulted systems for low-cost construction in Africa. ATDF Journal 2010;7(1/2):4-13.

[4] Davis L, Rippmann M, Pawlofsky T, Block P. Innovative Funicular Tile Vaulting; A Prototype in Switzerland. The Structural Engineer 2012;90(11):46-56.

[5] Block P, Bayl-Smith M, Schork T, Bellamy J, Pigram D. Ribbed tile vaulting Innovation through two design-build workshops. In: Gramazio F, Kohler M, Langenberg S, editors. FABRICATE 2014. ETH Zurich; 2014. p. 22-9.

[6] López López D, Domènech M, Palumbo M. "Brick-topia", the thin-tile vaulted pavilion. Case Stud Struct Eng 2014;2:33-40. https://doi.org/10.1016/j. csse.2014.09.001.

[7] López López D, Van Mele T, Block P. Tile vaulting in the 21st century. Informes de la Construcción 2016;68(544):e162. https://doi.org/10.3989/ic.15.169.m15.

[8] Ramage M, Hall TJ, Gatóo A, Al Asali MW. Rwanda Cricket Stadium: Seismically stabilised tile vaults. Structures 2019;18:2-9. https://doi.org/10.1016/j. istruc.2019.02.004.

[9] López López D, Van Mele T, Block P. The combination of tile vaults with reinforcement and concrete. International Journal of Architectural Heritage 2019; 13(6):782-98. https://doi.org/10.1080/15583058.2018.1476606.

[10] Heyman J. The stone skeleton. Int J Solids Struct 1966;2(2):249-79.

[11] Roca P, López-Almansa F, Miquel J, Hanganu A. Limit analysis of reinforced masonry vaults. Eng Struct 2007;29(3):431-9. https://doi.org/10.1016/j. engstruct.2006.05.009.
[12] Lourenço PB, Palacio K, Barros J. In: Design recommendations for reinforced masonry arches. Barcelona: International Center for Numerical Methods in Engineering (CIMNE); 2004. p. 583-92.

[13] Ramaglia G, Lignola GP, Prota A. Collapse analysis of slender masonry barrel vaults. Eng Struct 2016;117:86-100.

[14] Fabbrocino F, Ramaglia G, Lignola GP, Prota A. Ductility-based incremental analysis of curved masonry structures. Eng Fail Anal 2019;97:653-75. https://doi. org/10.1016/j.engfailanal.2019.01.027.

[15] Zampieri P, Simoncello N, Gonzalez-Libreros J, Pellegrino C. Evaluation of the vertical load capacity of masonry arch bridges strengthened with FRCM or SFRM by limit analysis. Engineering Structures; 225. 10.1016/j.engstruct.2020.111135.

[16] Zampieri P. Horizontal capacity of single-span masonry bridges with intrados FRCM strengthening. Compos Struct 2020;244:112238. https://doi.org/10.1016/j. compstruct.2020.112238.

[17] Block P. Thrust Network Analysis: Exploring Three-dimensional Equilibrium. PhD dissertation. Cambridge, USA: Massachusetts Institute of Technology; 2009.

[18] Block P, Ochsendorf J. Thrust network analysis: a new methodology for threedimensional equilibrium. Journal of the International Association for shell and spatial structures 2007;48(3):167-73.

[19] Van Mele T, Lachauer L, Rippmann M, Block P. Geometry-based understanding of structures. Journal of the International Association for Shell and Spatial Structures 2012;53(4):285-95.

[20] Rippmann M, Lachauer L, Block P. Interactive Vault Design. Int J Space Struct 2012;27(4):219-30. https://doi.org/10.1260/0266-3511.27.4.219.

[21] Block P, Lachauer L. Three-dimensional funicular analysis of masonry vaults. Mech Res Commun 2014;56:53-60. https://doi.org/10.1016/j. mechrescom.2013.11.010.

[22] Fraternali F. A thrust network approach to the equilibrium problem of unreinforced masonry vaults via polyhedral stress functions. Mech Res Commun 2010;37(2): 198-204. https://doi.org/10.1016/j.mechrescom.2009.12.010.

[23] Vouga E, Höbinger M, Wallner J, Pottmann H. Design of self-supporting surfaces. ACM Trans Graphics 2012;31(4):1-11. https://doi.org/10.1145/ 2185520.2185583.

[24] de Goes F, Alliez P, Owhadi H, Desbrun M. On the equilibrium of simplicial masonry structures. ACM Trans Graphics 2013;32(4):1-10. https://doi.org/ 10.1145/2461912.2461932.

[25] Maxwell JC. On reciprocal figures and diagrams of forces. Philosophical Magazine and Journal Series 1864;4(27):250-61.

[26] CEN. Eurocode 2: Design of concrete structures. EN 1992-1-1: 2004. Brussels: European Committee for Standardization, CEN; 2004.

[27] CEN. Eurocode 6: Design of masonry structures. EN 1996-1-1: 2005. Brussels: European Committee for Standardization, CEN; 2005.

[28] Van Mele T, Liew A, Méndez Echenagucia T, Rippmann M. COMPAS: A framework for computational research in architecture and structures. ETHZ: Block Research Group; 2017.

[29] Oval R, Rippmann M, Van Mele T, Baverel O, Block P. Patterns for Masonry Vault Design. Proceedings of the IASS Symposium 2017. Hamburg; 2017.

[30] Oval R, Rippmann M, Mesnil R, Van Mele T, Baverel O, Block P. Topology Finding of Structural Patterns. In: Hesselgren L, et al., editors. Proceedings of Advances in Architectural Geometry (AAG). Chalmers University of Technology, Department of Architecture and Civil Engineering. Vienna: Klein Publishing GmbH Gothenburg; 2018, p. 342-363.

[31] Oval R, Rippmann M, Mesnil R, Van Mele T, Baverel O, Block P. Feature-based Topology Finding of Patterns for Shell Structures. Autom Constr 2019;103: 185-201. https://doi.org/10.1016/j.autcon.2019.02.008. 